\title{
GEHEIMBÜNDELEI UND SOZIALE BEWEGUNG
}

\author{
ZUR GESCHICH'TE DES \\ „JUNGEN DEUTSCHLAND” IN DER SCHWEIZ
}

Die revolutionären Pariser Ereignisse vom Juli 1830 entfachten in den Staaten des Deutschen Bundes von neuem eine politische Bewegung, vor allem in den Reihen der bürgerlichen Jugend. Die Regierungen schritten sofort, insbesondere gegen die Tätigkeit radikaler Burschenschafter, mit äußerster Strenge ein. Die Androhung und Verhängung schwerer Kerkerstrafen ließ bald die Zahl der Flüchtlinge aus studentischen Kreisen und Journalistenzirkeln ansteigen. Das Ziel dieser Emigranten, die sich über die Grenzen in Sicherheit brachten, war neben Belgien und Frankreich die Schweiz. Hier, in den verschiedenen Kantonen, trafen die Deutschen mit zahlreichen Leidensgefährten aus Italien und Polen zusammen. „Alle beseelte der glühende $\mathrm{Haß}$ gegen ihre Unterdrücker. Alle waren von ihren Regierungen verjagt, in der kleinen Schweiz zusammengewürfelt; was konnten sie Besseres tun, als zu konspirieren". ' Mit diesen Worten kennzeichnete ein zeitgenössischer Beobachter die Atmosphäre, in der die Neuankömmlinge lebten und darangingen, Zukunftspläne für die Befreiung ihrer Länder zu schmieden.

Die eindrucksvollste Persönlichkeit unter diesen Heimatlosen war zweifellos Giuseppe Mazzini, der 1831 in Marseille den Bund des "Jungen Italien" (Giovine Italia) gegründet hatte. Er erstrebte als einer der radikalen geistigen Führer des Risorgimento die Errichtung einer unabhängigen, geeinigten Italienischen Republik, in der die Herrschaft der fremden Dynastien und des Adels durch eine freiheitliche Verfassung auf der Grundlage der Gleichberechtigung aller abgelöst werden sollte. Das gesamte Volk, auch die unteren Klassen, hatte nach seiner Theorie in einer großen Nationalbewegung aufzugehen. Allgemeine Volksaufstände, aus örtlichen bewaffneten Auseinandersetzungen hervorgehend, sollten schließlich alle italienischen Staaten erfassen und die endgültige Befreiung des Landes erzwingen. Mit Hilfe einer von ihm geschulten kleinen und disziplinierten,

1 Wilhelm Marr, Das junge Deutschland in der Schweiz. Ein Beitrag zur Geschichte der geheimen Verbindungen unserer Tage, Leipzig I 846, S. 26. 
zur Aktion entschlossenen Elite, hoffte Mazzini, in einem „Kreuzzug” die Massen zum Aufstand zu führen. Das "Junge Italien", eine nach dem Muster der Carbonari aufgezogene Geheimverbindung, sollte diesen Kampf vorbereiten und schließlich auch führen. ${ }^{1}$ Durch politische Erziehung und dauernde revolutionäre Aufstände glaubte Mazzini sein Ziel zu erreichen. Über ganz Italien waren die einzelnen Zellen seiner Organisation verteilt, die untereinander in Verbindung standen und gemeinsam auf die Lösung der italienischen Frage hinarbeiteten.

Mit den Auffassungen des ehemaligen Mitarbeiters von Babeuf und Berufsverschwörers Philippe Buonarroti, der 1832 in Italien ebenfalls eine Geheimgesellschaft „Veri Italiani” gegründet hatte, konnte sich Mazzini freilich nicht befreunden, obwohl sie ähnliche Ziele verfolgte wie das „Junge Italien”. Er warf den Anhängern der „Veri Italiani” eine zu große Abhängigkeit von Frankreich vor. Als italienischer Patriot betonte Mazzini nachdrücklich, daß ein wirklicher Fortschritt der Völker nur in einer Emanzipation von Frankreich liegen könne, in einer bewußten Distanzierung vom 18. Jahrhundert und der Großen Revolution von $1789 .^{2}$

Als Endziel schwebte ihm aber die Wiedergeburt der gesamten Menschheit vor. Er wollte der Heiligen Allianz der Herrscher eine Allianz der Jugend Europas entgegenstellen. Dieser Gedanke einer Verbrüderung der Völker gegen Fürstenwillkür führte in der Schweiz zur Gründung ,einer Assoziation von Menschen, die an die Zukunft der Freiheit, Gleichheit und Brüderlichkeit für die ganze Menschheit glaubten und ihr Denken und Handeln der Herbeiführung dieser Zukunft weihen wollten". ${ }^{3}$ In einer feierlichen Zeremonie wurde am I5. April I834 im Hause Mazzinis in Biel (Kanton Bern) dieser „Völkerbund", in dessen Reihen Deutsche, Franzosen, Italiener, Polen und Schweizer, nach Nationalitäten gruppiert, versammelt waren, unter dem Namen das "Junge Europa” ins Leben gerufen. „Es ist das Junge, Europa der Völker, das an die Stelle des alten Europas der Könige treten wird. Es ist dies der Kampf der jungen Freiheit gegen die alte Sklaverei, der Kampf der jungen Gleichheit gegen die alten Privilegien, der Sieg der neuen Ideen über den alten Glauben". So lautete der Leitsatz der Verbrüderungsakte." Mazzini verstand es auch,

${ }^{1}$ Politisches Programm vom 1831, in: Giuseppe Mazzini, Scritti (Edizione Nazionale), Imola igo6, Bd. II, S. $45 \mathrm{f}$.

${ }^{2}$ Arthur Lehning, Buonarroti and his international secret societies, in: International Review of Social History, Bd. I (1956), S. 138.

3 Aufruf vom I5. April 1834. Adolf Saager, Giuseppe Mazzini. Die Tragödie eines Idealisten, Zürich 1935, S. I Io. Der Aufruf war in deutscher, französischer, italienischer und polnischer Sprache verfaßt.

${ }^{4}$ Verbrüderungsakte vom I s. April 1834 . Saager, Giuseppe Mazzini, S. I 2 f. 
die nationalen Ideale der Unabhängigkeit mit dem Gedanken einer allgemeinen internationalen Völkerversöhnung zu vereinigen. Das „Junge Europa" verkündete die Grundsätze der Freiheit, Gleichheit und Humanität. An der Spitze des Programms standen die Glaubensartikel: Ein einziger Gott, ein einziger Herrscher = Gottes Gesetz; ein einziger Ausleger dieses Gesetzes = die Menschheit. ,Jung ist mehr als ein Wort", sagte Mazzini, „es ist ein Programm, es drückt uns allen verständlich aus, daß es hauptsächlich der jüngeren Generation vorbehalten ist, die Wiedergeburt Europas zu bewirken". ${ }^{1}$

Dèr italienische Volkstribun begrüßte auch den vierten Stand, dessen Existenz sich ja schon im Verlaufe der Pariser Julirevolution eindringlich bemerkbar gemacht hatte. Er wollte die proletarischen Elemente aber lediglich als Kampftruppe in seine nationale Bewegung einspannen. Denn der Sozialismus war für ihn nur ein Mittel, um die Massen zu gewinnen. Ihm erschien es als selbstverständlich, daß aus den drei unverletzlichen Grundrechten des "Jungen Europa”, der Freiheit, Gleichheit und Humanität auch eine vollkommene Lösung aller sozialen Probleme hervorgehen müsse. Der Gleichheitsbegriff wurde von Mazzini auch so verstanden, daß es für alle gleiche Rechte und Pflichten gäbe und jedem ein im Verhältnis zu seiner Arbeitsleistung stehender Anteil an dem Genusse des gemeinsamen Vermögens zustände. ${ }^{2}$

Trotz des scheinbar internationalen Charakters seiner Bewegung legte er keinen Wert darauf, die Nationen in dem Gesamtverbande eines einigen Europa aufgehen zu lassen, da ja jede einzelne ihre heilige Mission zu erfüllen hatte. Das "Junge Europa" sollte die Menschheit so organisieren, daß sie durch stetigen Fortschritt die höchste Vollkommenheit erreichte. Jedes Volk mußte dabei selbständig seine eigenen Aufgaben lösen, um das erstrebte Endziel der allgemeinen Verbrüderung zu erlangen. ${ }^{3}$

Die europäischen Herrscher und ihre Kabinettsminister betrachteten Mazzini als demagogischen Unruhestifter und gewissenlosen Verschwörer. Seine Anhänger aber sahen in ihm eine überragende Führerpersönlichkeit. Für den Aufbau des "Jungen Europa" behielt der italienische Freiheitskämpfer manches von der Verschwörungstaktik der Carbonari bei, denen er ja selbst einmal angehört hatte. Obwohl er viele dieser Methoden veraltet fand, sollte sich die Tätigkeit der von ihm beeinflußten Gesamtorganisation ebenfalls im Geheimen vollziehen. Die Mitglieder erhielten Tarnnamen, mußten

${ }^{1}$ Bundesurkunde des "Jungen Europa" v. I s. April 1834. Saager, Mazzini, S. I s 5 ff.

2 Glaubensartikel des "Jungen Europa". Mazzini, Scritti, Bd. II, S. 97.

${ }^{3}$ Otto Voßler, Mazzinis politisches Denken und Wollen in den geistigen Strömungen seiner Zeit (Beiheft der Historischen Zeitschrift), München 1927, S. 48 f. 
einen feierlichen Treueschwur ablegen und sich Waffen sowie Munition beschaffen. Verrätern drohte der Tod und jeder einzelne Teilnehmer wurde im Unklaren sowohl über die Führung als auch über deren Zukunftspläne gelassen.

Die drei Gruppen das "Junge Deutschland", das "Junge Polen" und das "Junge Italien" waren unabhängig in ihrer Verwaltung, hatten aber den Wahlspruch des "Jungen Europa" zu beherzigen und das gleiche Ziel, „die Befreiung ihrer Länder von der Fürstenherrschaft", zu verwirklichen. An der Spitze jeder dieser Vereinigungen stand ein Nationalkomitee, das seinerseits der Bundesführung unterstellt war, in der Repräsentanten aller drei Nationalitäten vertreten waren.

Mazzinis verfrühte Forderung eines republikanischen, sich auf das Volk stützenden Einheitsstaates stand im schärfsten Gegensatz $\mathrm{zu}$ den bestehenden Regierungsverhältnissen in Europa. Seine mit einem verschwommenen Mystizismus durchtränkten Richtlinien konnten der Gesamtbewegung auch keine einheitliche Zielsetzung geben. Es war daher nicht zu vermeiden, daß sich jede Nationalität ihre eigenen Auffassungen zurechtlegte.

Der Einfluß Mazzinis wirkte sich besonders auf die gebildeten Kreise der italienischen Jugend aus, die sein faszinierendes Wesen mit Idealismus und Hingabe an hohe Ziele erfüllte, zur politischen Aktivität anregte und so auch in ihnen das Verlangen nach staatlicher Einheit erweckte. Die Mitglieder des "Jungen Italien" hielten sich in der Mehrzahl außerhalb der schweizer Grenzen auf, in den italienischen Mittel- und Kleinstaaten. Über diese Anhänger herrschte Mazzini fast unumschränkt, denn unter ihnen war seine Autorität gefestigt. Weniger stark erwies sich seine Wirkung auf die polnischen Emigrantengruppen, die in der Hauptsache aus Offizieren und Mannschaften der ehemaligen polnischen Nationalregimenter bestanden, deren Überreste nach dem von der russischen Armee niedergeschlagenen Aufstand von 1830 ins Ausland geflohen waren. Die meisten dieser Polen hatten sich außerdem nicht in der Schweiz, sondern in Frankreich niedergelassen.

Die Führung der etwas später begründeten "Jungen Schweiz" brachte von Anfang an gegenüber den Mazzinischen Forderungen einer gesamteuropäischen Erneuerung starkes Mißtrauen zum Ausdruck. Sie plante lediglich, in den einzelnen schweizer Kantonen liberale Forderungen durchzusetzen, und hatte wenig Neigung, wegen der oft leichtsinnigen Revolutionsinszenierungen des ungeduldigen und leidenschaftlichen Italieners irgendwelche Gegenmaßnahmen europäischer Großmächte gegen die Schweiz heraufzubeschwören. 
Später entstanden auch ein "Junges Frankreich" und ein "Junges Spanien", die aber keinerlei Bedeutung erlangten. Ein "Junges Skandinavien" war geplant, kam aber nicht zustande. 1

Nach einem Bericht des Leiters des Mainzer Informations-Bureaus und Oberkommissärs der Wiener Polizeidirektion, Karl Noë, an die Kanzlei des Fürsten Metternich, soll in diesen Jahren das "Junge Italien" aus 86 Klubs bestanden haben, von denen sich 74 mit insgesamt 693 Mitgliedern in Italien aufhielten. Das , Junge Polen” umfaßte nach diesen Angaben 50 Klubs, wovon sich 19 in Polen betätigten. Das "Junge Frankreich" zählte nur I4 Klubs, die "Junge Schweiz" dagegen 62 mit etwa 480 Mitgliedern. Der größte Teil von ihnen lebte in den französischen Kantonen. Das "Junge Deutschland" hatte nur 14 Klubs, die sich auf die Schweiz und Frankreich verteilten. Von insgesamt I68 Mitgliedern wohnten nur 30 in Deutschland. ${ }^{2}$

Das „Junge Deutschland" war aber äußerst rührig, denn es arbeitete darauf hin, nach der Beseitigung der deutschen Kleinstaaterei eine große demokratische Republik zu errichten. Der Mitgliederbestand schien auch größer gewesen zu sein, als ihn Metternichs Gewährsmann bezifferte, dürfte aber dennoch die $\mathrm{Zahl}$ von 300 Anhängern nicht überschritten haben. Diese hielten außerdem untereinander nur eine lockere Verbindung aufrecht ${ }^{3}$. Die Mazzinischen „Glaubensartikel" sollten zwar auch in dieser Vereinigung das Denken und Handeln bestimmen, in Wirklichkeit war aber die gesamte Propaganda nur auf die Eigenart der deutschen Zustände ausgerichtet. Genau so wie die Polen, Schweizer und Franzosen standen auch die "Jungdeutschen" den humanistischen Zukunftsplänen Mazzinis skeptisch gegenüber. Denn auch ihre Interessen erstreckten sich in erster Linie nicht auf die gesamte Menschheit und besonders die europäischen Völker, sondern auf die unzulänglichen staatlichen, politischen und wirtschaftlichen Einrichtungen der engeren deutschen Heimat, die sie verbessern wollten.

Die treibende Kraft waren vor allem rakidale Burschenschafter, die sich hauptsächlich an der Universität Zürich niedergelassen hatten, dazu einige in Bern lebende Literaten und Journalisten. An der Spitze standen der ehemalige Militärarzt August Breidenstein und sein Bruder Friedrich, die beide aus Hessen-Homburg stammten

' S. Saager, Mazzini, S. I I I ff.

' Bericht Noës an den Fürsten Metternich vom 17. Juli 1 835 . Karl Glossy, Literarische Geheimberichte aus dem Vormäry. in: Jahrhuch der Grillparzer-Gesellschaft, Wien 19I2, Bd. I. S. XXXII.

${ }^{3}$ S. Gustav Freytag, Karl Mathy. Geschichte seines Lebens (Gesammelte Werke. zweite Auflage, Bd. 22), Leipzig 1898. S. 113. 
Sie hatten sich aktiv am Frankfurter Wachensturm vom 3. April 1833 beteiligt und mußten daraufhin fliehen. Dazu kam der Badenser Journalist Franz Strohmeyer, ehemaliger Herausgeber der radikalen Zeitschrift „Wächter am Rhein”; außerdem zwei Pfälzer, der Lehramtskandidat Nast und der Rechtskandidat Karl Theodor Barth sowie ein früherer Greifswalder Burschenschafter und Student der Jurisprudenz, Georg Peters. Aus den Reihen der leitenden Mitglieder ragten noch besonders hervor Georg Fein, Ernst Johann Hermann von Rauschenplatt, Gustav Kombst und Harro Harring. Ihnen gesellte sich später noch Karl Schapper zu, ein Forststudent aus Gießen, der sich in Hessen der umstürzlerischen Vereinigung „Gesellschaft der Menschenrechte" angeschlossen und sich Anfang I834 einer drohenden Verhaftung durch die Flucht in die Schweiz entzogen hatte. ${ }^{1}$

Es handelte sich meistens um keine überragenden Persönlichkeiten, sondern um Einzelgänger und zwiespältige Naturen, denen der Blick für die politischen Gegebenheiten fehlte. Fein hatte schon als Burschenschafter in Braunschweig unter den dortigen Handlungsgehilfen politische Propaganda getrieben. Er gehörte zu denjenigen Schriftstellern, die gemäß Bundestagsbeschluß als "Volksaufwiegler" $\mathrm{zu}$ betrachten waren und daher ,sowohl in Absicht auf ihre persönliche Aufführung als in Absicht auf ihre schriftstellerischen Gewerke" unter strenge politische Aufsicht gestellt wurden. ${ }^{2}$ Er war über Straßburg nach Paris gekommen und betätigte sich dort in einem deutschen „Volksverein". Dann reiste er in die Schweiz und trat in die Leitung des "Jungen Deutschland" ein. ${ }^{3}$

Viel radikaler als der gemäßigte, deutschtümelnde Fein gebärdete sich Rauschenplatt, der sich immer am wohlsten fühlte, wenn es zu revolutionären Aktionen kam. Er gehörte mit zu den Organisatoren des verwegenen und törichten Wachensturms in Frankfurt am Main, nachdem er schon kurz vorher an einem ebenfalls mißglückten Putsch in Göttingen teilgenommen hatte. Auch in seinem schweizer Asyl bemühte sich Rauschenplatt, durch politische Gewaltstreiche eine allgemeine Volkserhebung herbeizuführen. Dabei bedachte er niemals, daß seine Tätigkeit lediglich diejenigen schweizer Behörden-

\footnotetext{
1 August Wilhelm Fehling, Karl Schapper und die Anfänge der Arbeiterbewegung bis zur Revolution von I 848 . Von der Burschenschaft zum Kommunismus. Ein Beitrag zur Geschichte des Handwerkerkommunismus, Phil. Diss., Rostock 1922, Maschinenschrift, S. I $8 \mathrm{f}$.

${ }^{2}$ G. H. Schneider, Der Preß- oder Vaterlandsverein I832/33. Ein Beitrag zur Geschichte des Frankfurter Attentats (Veröffentlichungen des Archivs für die deutsche Burschenschaft Heft 4), Berlin I 897 , S. 96.

${ }^{3}$ S. Otto Oppermann, Georg Fein, ein Politiker der burschenschaftlichen Linken (Quellen und Darstellungen zur Geschichte der Burschenschaft und der deutschen Einheitsbewegung, Bd. 1), Heidelberg 1910, S. I $8 \mathrm{f}$.
} 
vertreter in ihrer gegnerischen Haltung bestärkte, die das Treiben der Emigranten mißbilligten und bei jeder Gelegenheit im Interesse der auswärtigen Beziehungen einen geeigneten Vorwand suchten, um mit strengen Maßnahmen gegen derartige Störenfriede vorzugehen.

Der ehemalige Sekretär beim Deutschen Bunde, Gustav Kombst - eigentlich von Kombst - hatte sich bei seiner früheren Dienststelle nicht nur durch eine allzu radikale demokratische Gesinnung verdächtig gemacht, was zu seiner Entlassung führte, sondern mußte überstürzt ins Ausland fü̈chten, weil er Abschriften von Bundesakten unterschlagen hatte. ${ }^{1}$ In der Schweiz war er als Journalist tätig und arbeitete ein Verfassungssystem für eine deutsche Föderativrepublik aus.

Harro Harring, ein früherer Steuerbeamter, hatte seinen Beruf aufgegeben, um Maler zu werden, widmete sich aber dann ganz der Schriftstellerei. Ein Fanatiker des Freiheitsgedankens, kämpfte er nach mancherlei Irrfahrten in Polen gegen die Russen und in Griechenland gegen die Türken. Für das "Junge Deutschland" dichtete er eine allgemein mit Begeisterung aufgenommene „deutsche Marseillaise":
„Auf, Auf! Ihr Deutschen löst die Bande -
Der Rache Tag durchstrahlt die Nacht!
O denkt des Elends, der Schmach und der Schande,
Des Verrats durch die fürstliche Macht.
Der Fürsten Göttlichkeit ist Lüge,
Im Bettler auch flammt Göttlichkeit;
Daß kein Fürst uns fortan mehr betrüge,
Steh'n wir alle zum Kampfe bereit." 2

In den Kreisen dieser Männer wurden ständig Zukunftspläne geschmiedet. ${ }^{3}$ Es war viel die Rede davon, durch einen bewaffneten Einfall im Heimatland eine Revolution hervorzurufen, die den ent-

${ }^{1}$ Dieses Material veröffentlichte er mit Kommentaren unter dem Titel: „Authentische Aktenstücke aus den Archiven des Deutschen Bundes zur Aufklärung über die hochverrätcrischen Umtriebe der deutschen Fürsten". Die erste Auflage erschien in einer Höhe von 4000 Exemplaren in Straßburg und war innerhalb von vierzehn Tagen vergriffen, da die Preußische Regierung jedes erreichbare Stück durch Mittelsmänner auf kaufen ließ. Die zweite Auflage erschien I 838 in Leipzig. Vgl. Kurt Glossy, Literarische Geheimberichte aus dem Vormärz, Bd. I, S. 39 .

${ }^{2}$ H. Buddensieg, Die Kultur dcs deutschen Proletariats im Zeitalter des Frühkapitalismus und ihre Bedeutung für die Kulturidee des Sozialismus, Lauenburg 1923, S. 56.

${ }^{3}$ Gute Charakteristiken finden sich in den Erinnerungen einer Tochter des ausgewiesenen braunschweigischen Publizisten Karl Weddo von Glümer: Claire von Glümer, Aus einem Flüchtlingsleben (1833-1839). Die Geschichte meiner Kindheit, Dresden und Leipzig I904, S. I 47 ff. 
scheidenden Umsturz herbeiführen sollte, und man stellte auch den Fürstenmord als sittlich gerechtfertigt hin. Bei den entscheidenden Beratungen hatten zunächst die überzeugten Demokraten in der Führung die Oberhand, die in Deutschland alle vorhandenen monarchischen Staatsformen abschaffen wollten. Die Erfüllung sozialer Wünsche wurde lediglich von einer demokratischen Staatsordnung erwartet, die neben der politischen auch soziale Gleichberechtigung bringen sollte. Denn an der bestehenden Ungleichheit konnten, wie auch an allen anderen Mißständen, nur die Fürsten die Schuld tragen. Jedes Mitglied erhielt daher die Aufgabe zugewiesen, überall republikanische Grundsätze propagandistisch zu verbreiten. Eine Betrachtung der schweizer Verhältnisse hätte die „Jungdeutschen” allerdings davon überzeugen müssen, daß die Errichtung einer Republik nicht gleichzeitig auch die wirtschaftliche Ungleichheit abschaffen würde.

Eine sozialistische Propaganda kam daher nicht in Frage. In einer Versammlung wies Fein sogar mit Entrüstung die Unterstellung zurück, jemals für die Verdoppelung der Freizeit und Lohnerhöhung eingetreten zu sein. Das sei „schändliche Lüge und Verleumdung”. 1 In einem Aufruf an die deutschen Bürger hieß es außerdem:,... Schützen wollen wir die Heiligkeit der Personen, des Eigentums, des Fleißes, schützen den lebendigen Quell des Gedankens, um welchen die Geschlechter sich lagern voll brennenden Durstes, schützen Bildung und Besitz und das gottempfangene Recht, das die Bürger des Staates verknüpft, wie der Liebe Band verwandte Herzen verkettet." 2 Aus derartigen Äußerungen ging eindeutig hervor, daß keine Pläne bestanden, die auf spätere Sozialisierungsmaßnahmen hinzielten.

Einer intensiven Tätigkeit der "Jungdeutschen” sollten aber bald Grenzen gesetzt werden. Am 27. Juli 1834 trafen sich nämlich in Steinhölzli, einer Wirtschaft in der Nähe von Bern, deutsche Intellektuelle und Handwerker, etwa 250 Personen, zu einer gemeinsamen Feier. Im Zeichen schwarz-rot-goldener Fahnen wurden leidenschaftliche Reden gehalten und Freiheitslieder gesungen wie:

„Gerechtigkeit, laß deine Fahnen wehen

hoch über Schutt und Blut.

Des Volkes Auge soll dieses Zeichen sehen, gepflanzt von Rächermut.

Wer brüderlich im Land der Brüder lebt,

'Vereinsversammlung vom 14. August 1834. In: Claire von Glümer, Aus einem Flüchtlingsleben, $S .149 \mathrm{f}$.

${ }^{2}$ Heinrich Schmidt, Die deutschen Flüchtlinge in der Schweiz und die erste deutsche Arbeiterbewegung $1833-1836$, Zürich 1899 . S. 55 . 
der teilt ein gleiches Heil.

Der Kopf, der frech sich aus dem Volk erhebt, den trifft des Volkes Beil!" 1

Das sah stark nach gefährlichen, revolutionären Umtrieben aus und zeigte außerdem, daß die Ende Mai I8 32 anläßlich einer Feierstunde des süddeutschen Liberalismus auf dem Hambacher Schloß verbreiteten Zielsetzungen trotz aller behördlichen Gegenmaßnahmen immer noch lebten und weiter propagiert wurden. Die deutschen Regierungen erhoben daraufhin sofort in Bern Einspruch. Denn hier auf dem Steinhölzlifest mit seinen überschwenglichen Reden und Gesängen mußte ja jedem neutralen Beobachter klar geworden sein, daß gewissenlose Demagogen den Handwerkern republikanischdemokratische Ideen einzuimpfen trachteten. Gerade aber von diesen in einem solchen Sinne bearbeiteten Wanderburschen, die ja meistens in ihre deutsche Heimat zurückzukehren pflegten, erwartete man, $\mathrm{da} ß$ sie den gewerblichen Mittelstand gefährlich politisieren würden. Die Gesuche der deutschen Bundesstaaten wurden daher immer dringlicher, doch wenigstens die Haupthetzer auszuweisen und dann die Vereine zu verbieten. Die Folgen dieser Bemühungen waren, daß einige Hauptbeteiligte und Organisatoren des Festes die Schweiz verlassen mußten, darunter auch Karl Schapper.

Den gesamten jungdeutschen republikanischen Bestrebungen war aber niemals Erfolg beschieden, genau so wie den hochfliegenden Projekten Mazzinis. Es gelang weder die Befreiung Italiens, Deutschlands oder Polens, noch konnte der Gedanke eines Bundes der europäischen Völker verwirklicht werden. Im Gegenteil, innerhalb der einzelnen Gruppen, besonders aber im "Jungen Deutschland", entstanden Mißtrauen und Argwohn. Über die Aktivität der Mitglieder äußerte ein Kritiker derartiger Bestrebungen: „Die ganze Tätigkeit war dahin gerichtet, vorzubereiten, die Gemüter mit $\mathrm{Haß}$ gegen die bestehenden Zustände zu erfüllen und sie für die Revolution empfänglich zu machen." 2 Es konnte daher nicht verwunderlich sein, daß die "Jungdeutschen" ständig auf der Hut vor Denunzianten oder Spitzeln sein mußten, und daß keiner dem anderen so richtig Vertrauen schenkte, obwohl der $\int 53$ der Statuten den Verrat als todeswürdig erklärte und jedes Mitglied zur Vollstreckung des Urteils verpflichtete. Das dauernde Konspirieren und die Vorbereitungen für künftige Putsche trugen wesentlich dazu bei, die Anhänger immer in Spannung zu halten und eine Aktivität vorzutäuschen, die

${ }^{1} \mathrm{H}$. Buddensieg, Die Kultur des deutschen Proletariats im Zeitalter des Frühkapitalismus, S. 53 .

2 Wilhelm Marr, Das junge Deutschland in der Schweitz, S. Io2. 
in Wirklichkeit nicht vorhanden war. Diese Machenschaften führten nur dazu, daß in entscheidenden Situationen Führung und Gesamtorganisation versagten.

Von Anfang an nahm das "Junge Deutschland" eine besondere Stellung innerhalb des "Jungen Europa” ein. Die Führung legte Wert darauf, sich von Mazzinis Anschauungen auch öffentlich zu distanzieren. „Er (Mazzini) lebt im Verborgenen, so daß er schon darum wenig auf uns influieren kann. Bis jetzt hat er sich bloß über die Mittel und Wege mit uns benommen, wie das 'Junge Europa' auch in der Schweiz zu gründen sei..." Mit diesen Worten beruhigte ein Mitglied die Bedenken Rauschenplatts, der fürchtete, daß Mazzini genau so wie von seinen italienischen Landsleuten auch von den "Jungdeutschen" als Messias verehrt werden und einen unbürgerlichen, beinahe aristokratischen Zug in die Gesamtorganisation bringen wollte. Dem "Jungen Deutschland" sollte ausdrücklich das Ziel gesetzt werden, ,nicht bloß die in der Schweiz lebenden deutschen Patrioten, sondern auch diejenigen $\mathrm{zu}$ vereinigen suchen, welche anderwärts, namentlich in Deutschland selbst wohnen." 1

Die jungdeutsche Propaganda, der Mazzinis hoher Gedankenflug fehlte, wollte allgemein das mittlere und kleine Bürgertum ansprechen. Ein Aufruf „An die Unterdrückten Teutschlands”, der in hoher Auflage in den Staaten des Deutschen Bundes verbreitet werden sollte, mahnte zur Einigkeit gegen die Fürsten. In einem zweiten ähnlichen Flugblatt „An die teutschen Soldaten” wurden Offiziere und Mannschaften der Bundeskontingente aufgefordert, in die „Arme des Volkes zu sinken" und mit ihm „dem Morgenrot der Freiheit entgegenzuziehen". 2

Die Verteilung der Flugblätter kam aber nicht zustande, da die Sendung schon an den Grenzen beschlagnahmt wurde. Doch dadurch ließen sich die "Jungdeutschen" nicht entmutigen. Je weiter die Möglichkeit einer bewaffneten Aktion in die Ferne rückte, um so mehr wurden die Versuche verstärkt, durch Flugblätter und Streitschriften Propaganda zu treiben. Rauschenplatt, Kombst und vor allem der geistige Kopf der Hambacher Versammlung von 1832, August Wirth, der sich ihnen angeschlossen hatte, waren immer

\footnotetext{
- Auszug aus einem von der Polizei beschlagnahmten Brief des Studenten Eduard Scriba an Hermann Rauschenplatt vom 19. Januar 1835. Abgedruckt bei Alfred Stern, Geschichte Europas seit den Vcrträgen von I8 is bis zum Frankfurter Frieden von 1871 , Bd. IV (Zweite Abteilung, erster Band: Geschichte Europas von I 830-1848), 2. Auflage, Stuttgart und Berlin I92 I, S. $616 f$.

"Stern, Geschichte Europas, Bd. IV (II/r), S. 404 f. Der crste Aufruf war von August Breidenstein, der zweite von Karl Theodor Barth verfaßt.
} 
wieder bemüht, ihre Ideen zu verbreiten. Da die Grenzkontrollen in Baden und Württemberg manchesmal recht nachlässig gehandhabt wurden, wenn es sich um Bücher- und Zeitschriftenballen handelte, gelang es sogar, verbotene Literatur bis zum Zentrum des deutschen Buchhandels, nach Leipzig, durchzuschleusen, um auch von hier aus Zersetzungspropaganda zu treiben. Der Inhalt der Flugschriften bezog sich allgemein auf die Errichtung einer Republik und die Proklamierung politischer Forderungen wie parlamentarische Vertretung der gesamten Nation, Preßfreiheit, ungehinderte Religionsausübung sowie die allgemeine Wehrpflicht. Liberale und weltbürgerliche Zielsetzungen wurden leidenschaftlich verkündet, während die soziale Problematik der Zeit mehr geahnt und angedeutet, aber nicht näher erläutert wurde. Die Verfasser der Schriften begnügten sich meist damit, die Unterschiede zwischen Arm und Reich in den Vordergrund zu stellen und anzuprangern.

Nachdem die Brüder Breidenstein, Barth und Peters Ende 1834 wegen allzu aktiver politischer Betätigung ausgewiesen worden waren und Franz Strohmeyer die Schweiz freiwillig verlassen hatte, blieben nur noch wenige Mitglieder des Gründungsausschusses übrig. Es erfolgte daher die Einsetzung eines provisorischen Zentralkomitees, dessen Leitung die drei Gießener Burschenschafter Eduard Scriba, Karl Soldan und Ernst Schüler übernahmen. 1

Bisher war der Wirkungskreis des "Jungen Deutschland" äußerst beschränkt gewesen. Das sollte sich aber ändern, als die neue Führung bemüht war, ihre revolutionäre Propaganda auch in die Reihen der in der Schweiz lebenden deutschen Handwerker zu tragen, um die Schar der Anhänger zu verstärken. Die leitenden Männer, besonders Schüler, der übrigens auch am Frankfurter Wachensturm teilgenommen hatte, waren sich darüber im klaren, daß sie ihre Zukunftspläne nur mit Hilfe einer Massenbewegung verwirklichen konnten. Die Frankfurter Ereignisse hatten ja zur Genüge bewiesen, daß sich mit einer Handvoll schlecht bewaffneter Studenten, die wenig Rückhalt in breiten Volksschichten zu erwarten hatten, keine Erfolge erzielen ließen.

Der Zuwachs aus Handwerkerkreisen war auch, wie erwartet, beachtlich. Denn eine sich immer mehr ausdehnende Textilindustrie in der Umgebung von Zürich verdrängte viele kleinere Betriebe.

'S. Otto Brugger, Geschichte der deutschen Handwerkerveteine in der Schweiz 1836 1 843. Die Wirksamkeit Weitlings I 841-I 843, Bern und Leipzig 1932, S. I8. Dieses Werk ist als grundlegend für die Beurteilung des Treibens der deutschen Handwerkervereine zu betrachten, besonders in der Zeit Weitlings. Die Tätigkeit der „Jungdeutschen” wurde dabei bewußt nur gestreift. 
Eine größere Anzahl selbständiger Handwerker wurden arbeitslos, und es entstand so in der Schweiz, wenn auch langsam und im kleinen Maßstabe, eine proletarische Schicht, genau so wie in den größeren europäischen Industrieländern.

„Wir haben keinen Krieg gehabt, haben keine Schulden, keinen Hof, und die Tändeleien mit dem Militär kommen nicht in Betracht. Und doch nimmt die Armut zu mehr und mehr." So klagte der Dichter Jeremias Gotthelf über die Verarmung, die er als „eine krebsartige Wunde im Völkerleben, ein eigentliches Pestübel unserer Zeit" bezeichnete. ${ }^{1}$

Die Not wurde noch durch das Überangebot von Handwerkern aller Art verstärkt, die neben den politischen Flüchtlingen aus Deutschland in die Schweiz eingeströmt waren: Buchbinder und Drucker, Maler, Schreiner und Schlosser, Schneider und Schuhmacher. Es handelte sich meistens um Gesellen, die in ihrer Heimat beruflich nicht weiter gekommen waren und aus diesem Grunde auf die Wanderschaft gingen, von den Gendarmen argwöhnisch beobachtet. Von Ort zu Ort ziehend, um sich nach den Arbeitsverhältnissen zu erkundigen, standen diese Gesellen unter ständiger behördlicher Kontrolle. Sie waren gezwungen, ihre Anwesenheit in einer Stadt in den Wanderbüchern bescheinigen zu lassen, um unter Umständen sofort abgeschoben zu werden, wenn sie nicht eine Mindestsumme Bargeld als Bezitz nachweisen konnten. In der Schweiz dagegen hofften die Handwerker, wenigstens der dauernden Überwachung mit ihren Schikanen ledig zu sein. Aber auch in dieser Hinsicht sollten sich nicht alle Wünsche erfüllen.

Unabhängig von dem "Jungen Deutschland" hatten einige aktive Handwerksburschen ihre eigenen landsmannschaftlichen Vereinigungen gegründet. In der Hauptsache handelte es sich um unpolitische Klubs, Lesezirkel und Gesangsvereine. Hier konnten auch Zeitungen und Bücher gelesen und ausgeliehen werden. In den Vereinsräumen fanden sich die intelligentesten Mitglieder zusammen, die sich nicht nur mit den Schwierigkeiten und Mühsalen des Berufslebens, sondern auch mit politischen und sozialen Angelegenheiten befaßten. ${ }^{2}$ Von einem wirklichen Verständnis für die sozialen Probleme konnte aber noch nicht die Rede sein. Erst später, mit dem Auftauchen Wilhelm Weitlings, verband sich eine schärfere Radikalisierung, die sich auch in einer Propagierung sozialistischer und kommunistischer Gedankengänge äußerte.

${ }^{1}$ Jeremias Gotthelf, Die Armennot, Bern 1838 , S. 16.

2 Der älteste Arbeiterverein war der 1833 gegründete Leseklub in Biel (Kanton Bern), der etwa 40-50 Mitglieder hatte. An seinem Aufbau war Ernst Schüler maßgebend beteiligt. S. Schmidt, Die deutschen Flüchtlingsvercine in det Schweiz, S. 77. 
Hier in diesen Kreisen glaubte die jungdeutsche Führung den geeigneten Boden für eine erfolgreiche Mitgliederwerbung gefunden zu haben. Die Tätigkeit ihrer Mittelsmänner wurde daher reger. Besonders auf den Landstraßen und in den Wirtshäusern sah man sich nach neuen Gesinnungsfreunden um. ${ }^{1}$ Die Methoden der Bearbeitung deutscher Handwerksgesellen zu revolutionären Zwecken zog aber sofort die Aufmerksamkeit der zuständigen Zentralbehörde des Deutschen Bundes in Frankfurt am Main auf sich. Ein ausführlicher Bericht wies besonders auf die Eigenart jungdeutscher Tätigkeit hin: „Zu diesem Behufe drängten sich die flüchtigen Demagogen in die Gesellschaften und Trinkgelage der Handwerksburschen, lehrten sie revolutionäre Lieder singen, teilten aufrüherische Schriften unter ihnen aus, machten ihnen die grellsten Schilderungen des angeblich auf Deutschland und namentlich auf den gewerbetreibenden Klassen lastenden Drucks und Elends und forderten sie auf, das Joch der Fürsten abzuschütteln und für die allgemeine deutsche Republik zu kämpfen, wozu viele der betörten jungen Leute sich bereit erklärten." 2

Außerdem erhöhte die übereifrige Aktivität auch die Besorgnisse der Kantonalbehörden, die Bedenken hatten, daß gewisse verproletarisierte schweizer Elemente aus Stadt und Land in die konspirativen Pläne der "Jungdeutschen" mit einbezogen würden. Diese dachten aber nicht daran, sondern beschränkten ihren Einfluß auf die deutschen Handwerker, die sie zu einer willigen Agitationstruppe erziehen wollten. „Die Handwerkervereine haben... nur eine lokale Stellung und Bedeutung. Sie sind nur Mittel, um in Deutschland unsere Grundsätze und Verbindung zu verbreiten", gestand Scriba ein. ${ }^{3}$ An eine Gleichberechtigung der Gesellen innerhalb der Bewegung war also nicht gedacht.

Die jungdeutsche Werbung hatte in den neuangesprochenen Kreisen Erfolge zu verzeichnen, denn es gab ja in der Schweiz viele deutsche Handwerker, die zusammenhielten, sich in bestimmten Gaststätten des öfteren versammelten und im Gespräch die schweize-

${ }^{1}$ Gustav Freytag, Karl Mathy, S. 8 5.

2 Memorandum der Bundeszentralbehörde vom 2. April i 836 , s. Karl Obermann, Zur Frühgeschichte der deutschen Arbeiterbewegung ( $\left.1833-188_{3} 6\right)$, in: Beiträge zum neuen Geschichtsbild. Zum 6o. Geburtstag von Alfred Meusel. Herausgegeben von Fritz Klein und Joachim Streisand, Berlin 1956, S. 213 . Obermann konnte für seine Abhandlung interessante Beiträge aus den Beständen des ehemaligen Preußischen Staatsarchivs, jetzt Deutsches Zentralarchiv II in Merseburg, benutzen, die allerdings zu einseitig ausgewertet wurden, um die These des Verfassers zu stützen, daß schon die damalige Arbeiterbewegung sich durch Reife, Geschlossenheit und Zielstrebigkeit ausgezeichnet hätte.

Scriba an Rauschenplatt, 19. Januar I835. Alfred Stern, Europäische Geschichte, Bd. IV (II/I), S. 6I 7 . 
rischen Verhältnisse mit denen ihrer Heimatländer verglichen, wobei die einzelnen Kantone allgemein recht gut abschnitten. Diese Gesellen, von denen nur wenige politische Flüchtlinge waren, trafen jetzt mit den intellektuellen Emigranten zusammen und diskutierten mit ihnen über die Zustände in Deutschland. Persönliche Freundschaften wurden geschlossen. Man versprach sich gegenseitige Hilfe und leistete sie nach Möglichkeit auch. In manchem der bisher unpolitischen Vereine und Lesekränzchen erlangten Studenten, Schriftsteller und Journalisten wegen ihrer überlegenen Bildung die Oberhand und besetzten hier einflußreiche Positionen, die es ihnen ermöglichten, eine Gruppe nach der anderen in ihr politisches Fahrwasser zu steuern.

Die ,Jungdeutschen" verstärkten außerdem ihren Einfluß dadurch, daß sie ebenfalls Lese- und Bildungsvereinigungen gründeten, um in gemütlichen Zusammenkünften mit Rundgesang und Vorträgen über die deutschen Verhältnisse einen größeren Kreis um sich zu scharen. Bei dieser Gelegenheit sollte nach im persönlichen Gespräch eine Auslese getroffen und die intelligentesten Handwerker ausgewählt und in besonderen Zirkeln zusammengefaßt werden. Während die übrigen Vereinsmitglieder von der Existenz dieser Gruppen nichts erfahren durften, wurden die Ausgewählten besonders geschult und mit verbotenen politischen Broschüren zur Weiterbildung versehen.

Unter den Parteigängern des "Jungen Deutschland" bestand bald Einverständnis darüber, daß ohne die Gewinnung der Handwerksgesellen kein erfolgreicher Werbefeldzug im Kampf um die Einheit und Freiheit Deutschlands geführt werden konnte. Ernst Schüler sah in den Handwerksburschen eine ausgezeichnete „Propaganda zu Fuß” und erklärte: „Das Felleisen auf dem Rücken, ein paar Batzen in der Tasche, den Knotenstock in der Hand, wandernd von Berlin nach Konstanz, von Wien nach Hamburg, verbreiteten sie in ihren Kreisen den Glauben an die Zukunft der Völkerfreiheit und die Ủberzeugung, daß gründliche Reformen notwendig seien." 1

Schüler war auch mit den Statuten, die ja noch von den Brüdern Breidenstein, Strohmeyer, Nast, Barth und Peters ausgearbeitet worden waren, nicht einverstanden. Denn das Gründungskomitee hatte lediglich eine republikanische Geheimverbindung aufbauen wollen, deren sorgfältig ausgewählte Mitglieder zu einer Elite ausgebildet werden sollten. Die Wünsche Schülers zielten aber dahin, auch die Handwerksgesellen stärker mit einzubeziehen. Ihnen sollten auch die gleichen Aufgaben gestellt werden wie den Burschenschaftern. Der Mediziner Ernst Dieffenbach, ebenfalls ein Student aus Gießen,

${ }^{1}$ Ernst Schüler, Die Regierung der Republik Bern und die Verfolgten der Könige. Als Verteidigung gegen eine Anklage auf „Hochverrat” vor den Gerichten und der öffentlichen Meinung. Ein Beitrag Berns im Jahre 1836 , Biel I 837 , S. 17 f. 
unterstützte diese Forderungen. Vor seiner Ausweisung hatte sich auch Karl Schapper für ähnliche Wünsche eingesetzt.

Je stärker die Mitgliederzahl der Gesellen innerhalb des "Jungen Deutschland" anstieg und die Anhängerschar der selbständigen Vereinigungen sich vergrößerte, um so mehr entstanden Meinungsverschiedenheiten über die Art einer ersprießlichen Zusammenarbeit. Die Handwerkervereine betonten ihre selbständige Stellung. Sie wollten die Leitung gern in der Hand behalten und nicht dem „Jungen Deutschland" allein überlassen. Ein Schreiben aus Genf an die Vereine der deutschen Arbeiter am Zürichsee sprach die Mahnung aus: „Ihr seid nun einmal mit ihnen (den ,Jungdeutschen”) in Unterhandlung getreten, prüfet ihre Einrichtung genau und suchet sie von etwas Besserem zu überzeugen, und wir hegen die Hoffnung, daß sie sich werden belehren lassen und uns gerne die Hand reichen; bedenket insbesondere, daß nur Eintracht stark macht, denn wo würden unsere Feinde so stark sein, wenn sie nicht einig wären?" 1

Die Mehrheit der "Jungdeutschen” wollte aber die selbständigen Vereine ganz ihrer eigenen Führung unterstellen als einfache Parteigänger, die zwar Befehle und Anordnungen auszuführen hatten, aber in keine Pläne über künftige Aktionen eingeweiht werden durften. In die Reihen des eigentlichen Geheimbundes sollten nur wenige, erprobte Handwerker aufgenommen werden. Die Zentralleitung konnte aber in den nächsten Wochen und Monaten ihren Einfluß auf die Vereine nicht in dem gewünschten Umfange verstärken. Andererseits gelang es diesen Gruppen auch nicht, einen Generalsekretär einzusetzen und mit dessen Hilfe die kleineren Klubs zu einer einheitlichen Organisation zusammenzufassen. ${ }^{2}$

Da laufend Handwerker in die Reihen des "Jungen Deutschland" aufgenommen wurden, erhielten diese Kreise zahlenmäßig bei weitem das Übergewicht. In Zürich bestanden z.B. 1836 vier Klubs mit zusammen 36 Mitgliedern, von denen aber nur sechs politische Flüchtlinge waren, während die übrigen eine handwerkliche Tätigkeit ausübten. ${ }^{3}$ Das proletarische Element nahm ständig zu, während die Zahl der Studenten und Intellektuellen zurückging. Die Folge war, $\mathrm{da} ß$ die Interessen der Mitglieder wechselten und bei den Diskussionen auch allgemeine Handwerkerbelange in den Vordergrund traten.

Diese Entwicklung führte wiederum zu einer Veränderung in den

\footnotetext{
'Schreiben vom 24. Februar i 834. Alfred Stern, Aus deutschen Flüchtlingskreisen im Jahre I836. Festgabe für Gerold Meyer von Knonau, Zürich 1913, S. 452.

${ }^{2}$ Brief der Bieler Vereinsleitung an den Leiter des Züricher Vereins vom 20. Oktober 1834. Karl Obermann, Zur Frühgeschichte der deutschen Arbeiterbewegung, S. 2 I 8 f. "Hans Gustav Keller, Das ,Junge Europa" 1834-1836. Eine Studie zur Geschichte der Völkerbundsidee und des nationalen Gedankens, Zürich und Leipzig 1938, S. 67.
} 
Reihen der Anhänger. Mancher Student und bürgerliche Flüchtling zog sich enttäuscht und verärgert zurück. Andere dagegen wurden angeregt, sich mehr als bisher mit sozialen Problemen zu befassen, um sich auf diese Weise der proletarischen Richtung anzunähern.

Die Diskussionszirkel erfreuten sich reger Teilnahme. Uber die politischen Ziele herrschte allerdings Unklarheit, da sich natürlich niemand vorstellen konnte, wie eine reine Arbeiter- und Handwerkerbewegung aufgezogen werden sollte. Denn der Begriff des Sozialismus hatte in diesen Kreisen noch keine politische Bedeutung, sondern äußerte sich lediglich in einem leidenschaftlichen Aufwallen gegen die Unzulänglichkeiten in der Welt. Außerdem wurde eine gesellschaftliche Neuordnung erstrebt, die auch dem zunächst noch bedächtig emporstrebenden vierten Stande zugute kommen sollte. Der Appell an das Gefühl fand dabei immer noch den stärksten Widerhall. Der Schlachtruf des katholischen Priesters Lamennais gegen die soziale Ungerechtigkeit, seine "Worte eines Gläubigen” verfehlten nicht nur in Frankreich, sondern auch in den schweizer Kantonen ihren Eindruck nicht. „Die Schrift von Lamennais ist wegen ihres in religiöses Gewand gekleideten Stiles von ungeheurem Einfluß, besonders auf die niederen Klassen des Volkes", berichtete ein preußischer Polizeiagent. 1

Ein neuer Zug sollte dadurch in die Bewegung kommen, daß zwei Studenten, der Jurist Friedrich Gustav Ehrhardt aus Eilenburg und der Mediziner Carl Cratz aus Nassau, unabhängig von den übrigen jungdeutschen Bestrebungen, eine sozialpolitische Vereinigung deutscher Arbeiter gründeten. Diese Gruppe unterhielt rege Beziehungen zu den in Paris ansässigen zahlreichen deutschen Handwerkern, besonders zu dem „Bund der Geächteten”, der in den letzten Jahren von einer zunächst rein bürgerlich-demokratischen Auffassung zu klassenbewußten sozialistischen Gedankengängen übergegangen war. Der äußerst rührige Ehrhardt, der seine preußische Heimat verlassen mußte, weil er an burschenschaftlichen Machenschaften in Halle und Greifswald beteiligt war, ${ }^{2}$ wollte die jungdeutsche Bewegung mit den sozialistischen Bestrebungen des „Bundes der Geächteten” koordinieren.

Mit Hilfe von Cratz gab er eine eigene Zeitschrift, „Das Nordlicht”, heraus. Dieses Organ, das wegen Geldmangels allerdings schon nach

${ }^{1}$ Bericht Ludwig Lessings vom 13. Juni 1834 . Abgedruckt in: Schmidt, Die deutschen Flüchtlinge in der Schweiz, S. Io9.

2 Am 21. Mai 1834 erließ die Preußische Regierung einen Steckbrief gegen ihn. S. L. Fr. Ilse, Geschichte der politischen Untersuchungen, welche durch die neben der Bundesversammlung errichteten Commissionen, der Central-Untersuchungs-Commission zu Mainz und der Bundes-Central-Behörde zu Frankfurt in den Jahren I819-1827 und 1833-1842 geführt sind, Frankfurt a. Main I860, Beilage II, S. VIII. 
wenigen Nummern sein Erscheinen einstellen mußte, ${ }^{1}$ war auf das Niveau der Handwerker abgestimmt und wurde in einem kosmopolitischen und republikanisch-antiklerikalen Sinne redigiert. Die Besitzlosen in Stadt und Land sollten beeinflußt werden, die als einzige imstande wären, revolutionäre Ziele auch zu verwirklichen. In einem zündenden Aufruf wurde vor allem das proletarische Klassenbewußtsein angesprochen; „Vertraut auf Euch selbst, Ihr Arbeiter, Handwerker und Bauern, die Ihr von Hochmut und Herrschsucht fern, in reger Tätigkeit ein anspruchloses Leben führt. Ihr seid der Kern des Volkes, an Euch ist's, den Wurm zu zertreten, der an dem innersten Marke des Volkes nagt; schüttelt sie ab, die Fesseln, die arbeitsscheue Müßiggänger Euch schmieden." 2

Neben dem „Nordlicht" 3 erschien auch noch „Die Junge Schweiz - La Jeune Suisse", das Organ der schon erwähnten Organisation gleichen Namens, in der sich radikal gesinnte schweizer Handwerker und auch Studenten gesammelt hatten. Diese zweisprachige Zeitschrift sollte die Jugend Europas für einen künftigen Völkerstaat heranbilden. Die einzelnen Nummern fanden daher, genau so wie „Das Nordlicht", besonderes Interesse bei den Zensurstellen der deutschen Regierungen. Als Redakteure wirkten neben Mazzini noch Ernst Schüler mit sowie der ehemalige Leiter des Pariser "Proscrit", Josef Garnier, der außerdem als Sprachlehrer tätig war. Hier schrieb auch der wegen seiner umfassenden Kenntnisse und seiner Zuverlässigkeit in Emigrantenkreisen sehr geschätzte spätere badische Ministerpräsident Karl Mathy. ${ }^{4}$

Der Vertrieb der Zeitschrift ließ aber wegen ihres Inhalts, der sich hauptsächlich auf schweizer Verhältnisse bezog, zu wünschen übrig. Ihre Wirkung im deutschen Sprachgebiet konnte wegen dieser Einseitigkeit auch nur gering sein. „... Das Journal 'Die Junge Schweiz' hat hier nur wenig Abonnenten", schrieb ein Agent des Mainzer Informationsbüros aus Straßburg. „,Die hohlen Abstraktionen Mazzinis sagen dem Volke nicht $\mathrm{zu}$, die lebendige Wirklichkeit ist ihm lieber; aufrichtig gesprochen versteht man im Elsaß jene politische Weisheitslehre viel zu wenig." 5

${ }_{1}^{1}$ Die erste Nummer erschien Januar 1835 , die zweite im Frühjahr, die letzte im September 1835.

2 Das Nordlicht, Nr. I vom Januar i 835 .

s Die Auflage betrug etwa 2000 Exemplare; davon wurden 1400 nach Deutschland geschickt, wie aus einem Bericht des Ministerresidenten der vier freien Städte Deutschlands, Vincent Rumpff, vom 12. Januar 1834 hervorging. In: Stern, Europäische Geschichte, Bd. IV (II/I), S. 466.

- Gustav Freytag, Karl Mathy, S. 418

- Bericht aus Straßburg, März 1836. Karl Glossy, Literarische Geheimberichte aus dem Vormärz, Bd. II, S. 75 . 
Cratz wollte schließlich alle deutschen Arbeitervereine in der Schweiz zu einer Einheit zusammenfassen. Er und Ehrhardt rieten vor allem davon ab, die Mitglieder des "Jungen Deutschland" an abenteuerlichen Unternehmungen teilnehmen zu lassen, wie sie Mazzini liebte. ${ }^{2}$ Der Vorschlag der beiden Freunde, eine öffentliche Zentral- und Propagandaorganisation zu schaffen, stieß aber im Zentralkomitee auf Widerspruch. Aus den Reihen des Pariser „Bundes der Geächteten", dessen Mitglieder ja schon einige Erfahrungen sammeln konnten, kam sogar der Rat, auf jeden Fall bei der alten Form des Geheimbundes zu bleiben. Es mußte ja die Verbindung mit der deutschen Heimat aufrechterhalten werden, in der jegliche politische Vereinsbildung unmöglich war und nur die zurückkehrenden Handwerksburschen die Möglichkeit hatten, heimlich zu werben. Ein Verein, der sich in der Öffentlichkeit betätige, müsse daher abgelehnt werden, weil ,auch die kleinste Sache von Wichtigkeit im voraus bekannt wird". ${ }^{2}$ Die Cratzschen Pläne scheiterten zunächst. Verschiedene jungdeutsche Mitarbeiter trennten sich sogar von ihm.

Die Entwicklung nahm jetzt überhaupt einen ganz anderen Verlauf, als ihn sich die "Jungdeutschen" vorgestellt hatten. Die romantischen Gedanken einer revolutionären Erhebung um jeden Preis wurden von den neuen Anhängern aus Handwerkerkreisen immer mehr abgelehnt. Viele wollten auch von der blutrünstigen Phraseologie in der Propaganda nichts mehr wissen. Ein Teil der Mitglieder wandte sich sogar scharf gegen die Geheimbündelei, die durch eine andere Organisationsform abgelöst werden sollte. Sie forderten auch, die Agitation nicht mehr gegen einzelne regierende Persönlichkeiten zu richten und den Fürstenmord zu verherrlichen, sondern das gesellschaftliche System als Ganzes anzugreifen. ${ }^{3}$

Der Züricher Verein verlangte vor allem eine grundlegende Änderung der Statuten des „Jungen Deutschland" und die Anpassung an die Wirklichkeit, d.h. die vollständige Trennung von Mazzinis "Jungem Europa". Anfang I 836 wurde das Zentralkomitee des ,Jungen Deutschland" von Bern nach Biel verlegt. Die Leitung erhielt Ernst Schüler, der inzwischen schweizer Bürger geworden war und als Lehrer am dortigen Gymnasium Unterricht in Geschichte und Naturkunde erteilte. Als Mitbegründer der „Jungen Schweiz” legte

${ }^{1}$ Schreiben vom 24. Februar 1835 an die Vereine der deutschen Arbeiter am Zürichsee. Alfred Stern, Aus deutschen Flüchtlingskreisen im Jahre 1835, S. 453.

${ }^{2}$ Adolf Roth an Ehrhardt, 21. Januar 1835. Stern, Aus deutschen Flüchtlingskreisen, S. 458 .

${ }^{3}$ S. das Kreisschreiben des geschäftsführenden Ausschusses zu Bicl vom Frühjahr 1836. Alfred Stern, Europäische Geschichte, Bd. IV (II/I), S. 396 ff. 
er auch Wert darauf, eine Personalunion zwischen ihr und dem "Jungen Deutschland" herbeizuführen.

Schüler unterstützte auch weiterhin die selbständigen Handwerkervereine und kam ihren Wünschen und Bestrebungen entgegen, ohne aber die führende Stellung der "Jungdeutschen" beschränken zu lassen. Die Mitgliederzahl der verschiedenen Klubs wurde jetzt auf 268 beziffert. 1

Am 27. Mai i 836 fand in Brugg, einem kleinen Orte im Kanton Solothurn eine Konferenz statt. Es wurde hier beschlossen, doch die Statuten in einem Sinne, der den früheren Anregungen von Ehrhardt und Cratz entsprach, umzuarbeiten. Das Redaktionskomitee strich alle Paragraphen, die sich mit der geheimen Vorbereitung von Aufständen befaßten sowie die Pflichten zur allgemeinen Bewaffnung. Es fiel auch die Bestimmung, die Verrätern von Bundesgeheimnissen die Todesstrafe androhte. Zwar unterblieb eine ausdrückliche, schriftlich festgelegte Trennung von Mazzinis Organisation, aber praktisch war sie vollzogen. ${ }^{2}$ Das "Junge Deutschland" hatte sich damit $\mathrm{zu}$ einem ausgesprochenen Handwerkerverein entwickelt, der republikanisch-demokratische und sozialistische Ziele verfolgte. Die Zusammensetzung der Mitglieder blieb aber nach wie vor uneinheitlich, da sich neben ausgesprochenen Industriearbeitern noch die dem Kleinbürgertum zugehörigen Handwerksgesellen und auch ehemalige Meister zusammenfanden, die sich dem Mittelstand noch verbunden fühlten. Diesen Kreisen mußten die "Jungdeutschen" in der Führung jetzt mehr Einfluß einräumen, während die Intellektuellen in den Hintergrund traten. Das führte dazu, daß sich Mitglieder wie Fein und Harro Harring benachteiligt fühlten. Außerdem befürchteten sie ein Erstarken der „kommunistischen” Einflüsse. ${ }^{3}$ Beide traten daher aus. Andere Gesinnungsgenossen folgten ihrem Beispiel.

Die Handwerker hatten zwar das ständige Pläneschmieden für Putsche und bewaffnete Überfälle aufgegeben. Aber sie waren mehr denn je davon überzeugt, daß lediglich eine große revolutionäre Erhebung die Entscheidung und damit auch die gewünschte Veränderung der Verhältnisse herbeiführen könnte. Die politische Aufklärung sollte daher verstärkt und der Aufbau der Gesamtorganisation gefestigt werden. Es war geplant, die „Propaganda zu Fuß” der Handwerksburschen, auf die allergrößter Wert gelegt wurde, in Deutschland noch mehr

IS. Karl Obermann, Zur Frühgeschichte der deutschen Arbeiterbewegung, S. 223.

${ }^{2}$ S. Otto Brugger, Geschichte der deutschen Handwerkervereine in der Schweiz, S. 27.

${ }^{3}$ Harro Harring, Historisches Fragment über die Entstehung der Arbeiter-Vereine und ihren Verfall in communistische Spekulationen, London 1852 , S. 14 
zu fördern. Dabei mußte natürlich äußerst vorsichtig und heimlich vorgegangen werden, denn in den deutschen Mittel- und Kleinstaaten ließ sich eine derartige subversive Tätigkeit schnell aufdecken und unterbinden. Dazu gesellten sich noch besondere Schwierigkeiten im Umgang mit den in der Heimat ansässigen Handwerkern. Diese unterhielten sich zwar nach Feierabend manches Mal über sozialistische und kommunistische Theorien, von denen sie irgendwann einmal gehört hatten. Aber ihre Anschauungen hinsichtlich dieser Begriffe waren oft noch naiver und oberflächlicher, als die der Gesellen in der Schweiz. Ja, mancher Handwerker mußte erst in einem Lexikon nachschlagen, um sich über die Bedeutung der Worte zu unterrichten, ohne daß dadurch die Sache als solche klarer geworden wäre. 1

Für die Wanderburschen aus der Schweiz war es daher nicht leicht und wegen der allgemeinen polizeilichen Überwachung auch nicht ungefährlich, Propaganda zu treiben. Mancher der Gesellen hatte aber ein großes Geschick darin, besonders wenn er sich auf mündliche Berichte beschränkte, die, wenn sie eindringlich vorgetragen wurden, schon einige Wirkung erzielen konnten.

Bedrohlich für ihre Tätigkeit war außerdem das Mißtrauen, das die deutschen Kabinette und vor allem der österreichische Staatskanzler Fürst Metternich gegenüber der jungdeutschen Geheimbündelei bekundeten. Obwohl von einer aktiven Organisierung des Widerstandes gegen die Staatsgewalt nicht die Rede sein konnte, da es sich ja lediglich um kleinere Klubs ohne wirkliche Macht handelte, waren die Anstrengungen verschiedener deutscher Regierungen doch recht groß, um die schweizerischen Behörden zum Einschreiten zu bewegen. Allerdings ließ es sich nicht leugnen, daß in den Äußerungen der Emigranten auch gefährliches liberales und demokratisches Gedankengut zum Ausdruck kam, dessen Verkündung in den deutschen Staaten unter Strafe gestelit war. Die Bemühungen, besonders durch diplomatischen Druck auf die schwächeren schweizer Kantone die Auflösung der Vereine oder sogar die Ausweisung der Flüchtlinge zu erreichen, standen aber im grotesken Gegensatz zu der Wichtigkeit dieser Verbindungen, deren Stärke ja insgesamt auf etwa 250-300 Mitglieder zu beziffern war und die sich ausserdem untereinander noch uneinig und in ihren politischen Anschauungen wenig entwickelt zeigten. Boshaft bemerkte Kombst, die Schweiz

1S. die Aussagen des Schuhmachers Hätzel anläßlich des Kölner Kommunistenprozesses von 1852 . Wermuth u. Stieber, Die communistischen Verschwörungen des 19. Jahrhunderts. Im amtlichen Auftrag zur Benutzung der Polizeibehörden den sämtlichen deutschen Bundesstaaten auf Grund der betreffenden gerichtlichen und polizeilichen Akten dargestellt, Berlin 1853/'s4, Bd. I, S. 49. 
wäre „das gelobte Land der Diplomaten”, wo auch Stümper Lorbeeren ernten könnten. ${ }^{1}$ Die Vertreter des Deutschen Bundes glaubten aber, gerade hier eine umfassende Zentralorganisation entdeckt zu haben, die den Thronen gefährlich werden könnte. Eine Ausnahme bildete lediglich der Staatsminister des Großherzogtums Hessen und bei Rhein, Freiherr du Thil, der die Abgeordnetenkammer in Darmstadt mehr fürchtete als sämtliche Flüchtlingsorganisationen zusammengenommen: ${ }^{2}$ "Die Verschwörer sind Fanatiker", stellte er fest, „Menschen ohne Erfahrung, ohne Kenntnis des wahren Zustandes der Dinge; sie überschätzen eben deswegen ihre Kräfte, sie stehen heute noch außerhalb des Volkes. Erst in der Zukunft werden sie wichtig werden, bis dahin bilden sie ein sekundäres Übel."

Die Großmächte Österreich und Preußen reagierten besonders empfindlich, und mit allen gerade noch zulässigen Mitteln wurden die schweizer Kantone gezwungen, mißliebige Fremde noch stärker zu überwachen. ${ }^{3}$ Es ließ sich zwar nicht durchführen, das Betreten der Schweiz überhaupt zu verbieten. Zumindest konnte aber wenigstens der Besuch erschwert werden, wenn es sich um Handwerksburschen und Studenten handelte. Schon 1833 und 1834 hatte der Deutsche Bundestag verboten, an den Universitäten Bern und Zürich zu studieren. ${ }^{4}$ Eine etwas später durchgeführte Sperre für wandernde Handwerker konnte sich aber nicht in dem gewünschten Maße auswirken, zumal ja die Einwanderung von französischem Gebiete aus ungehindert erfolgen konnte. Fürst Metternich drängte aber immer wieder darauf, die Auswanderungsmöglichkeiten zu beschränken. Im Einverständnis mit dem Preußischen Hofe betonte er in einer Instruktion, „daß das von der revolutionären Propaganda in der neuesten Zeit angenommene verruchte System einer planmäßigen Verführung des Handwerkerstandes durch Vereine und mittels aufregender Versammlungen in seinen Folgen noch weit gefährlicher werden kann als die früheren, mehr auf die höheren Klassen der Gesellschaft gerichteten Verführungspläne der Umsturzpartei; daß es daher dringende Pflicht aller jener Regierungen ist, die ihnen anvertrauten Staaten vor langsam sich verbreitendem, aber desto gewaltsamer hervortretendem Umsturze schützen zu wollen, ihre jungen Handwerker vor dem Wandern nach solchen Ländern, in denen Vereine und

${ }^{1}$ Gustav Kombst, Erinnerungen aus meinem Leben, Leipzig I848, S. I87.

2 Kurt Wilhelm Heinrich Freiherr du Bos du Thil, Denkwïrdigkeiten. Herausgegeben von Heinrich Ullmann, Stuttgart und Berlin 1921, S. $47^{8} \mathrm{f}$.

${ }^{3}$ S. Alfred Stern, Geschichte Europas, Bd. IV, II/r, S. $396 \mathrm{f}$.

4 Protokolle der Deutschen Bundesversammlung vom Jahre 1833, Frankfurt a. M. 1834 ,

S. 463 f. und Protokolle vom Jahre 1834, Frankfurt am Main I 835 , S. 848 ff. 
Versammlungen der gedachten Art notorisch geduldet werden, abzuhalten..." 1 Die Folge der Metternichschen Warnungen war, daß die Frankfurter Bundesversammlung am is. Januar 1835 einstimmig beschloß, das Verbot des Gesellenwanderns durchzuführen.

Bei den sich verstärkenden polizeilichen Überwachungsmaßnahmen bewährte sich wiederum das Mainzer Informationsbüro. Noë, der unter dem Namen Nordberg auftrat, entwickelte in der Schweiz eine rege 'Tätigkeit. Seine Agenten standen überall bereit, um im „Kampf des ewigen Rechtes gegen das revolutionäre Prinzip" die politischen Rechte Österreichs und natürlich auch des übrigen Europa ,vor den unsinnigen Entwürfen einer tollkühnen und verworrenen Schar sicherzustellen." 2

Außerdem besoldete noch fast jede einzelne deutsche Gesandtschaft eigene Spitzel, die natürlich versuchten, durch wirkungsvolle Berichte die Besorgnisse ihrer Auftraggeber zu verstärken und sich bei dieser Gelegenheit unentbehrlich zu machen. Das galt auch für den Fall, daß eine Verschwörung oder die Androhung einer bewaffneten Grenzverletzung erst erfunden werden mußte.

Im Lauf der Zeit hatte sich die Struktur des Flüchtlingswesens verändert und war immer uneinheitlicher geworden. Zu den freiheitlich gesinnten Studenten und fleißigen Handwerkern gesellten sich auch Abenteurernaturen und zweifelhafte Existenzen, die sich als politisch Verfolgte ausgaben, was ja nicht immer überprüft werden konnte. Diese Elemente wollten bewußt im Trüben fischen. Aus ihren Reihen rekrutierten die verschiedenen polizeilichen Überwachungsstellen auch manchen Spitzel. Zu diesen gekauften Subjekten zählte auch ein Hochstapler, Zacharias Aldinger, der in der Öffentlichkeit als Baron von Eyb auftrat und sich als Kassierer und Sekretär der Züricher jungdeutschen Gemeinde gerade in den Handwerkerkreisen ein besonderes Vertrauen erworben hatte. Er besaß großen Einfluß, und es gelang ihm sogar, mit Mazzini persönlich in Verbindung zu treten. Nach eigenem Eingeständnis war Aldinger darum bemüht, „hauptsächlich die Handwerker an sich zu ziehen, denen er dann die verschiedenen revolutionären Flugschriften zur

\footnotetext{
${ }^{1}$ Instruktion vom 14. November 1834. Abgedruckt bei Obermann, Zur Frühgeschichte der deutschen Arbeiterbewegung, S. 221. Der Verfasser glaubt aus den Äußerungen Metternichs zu erkennen, daß „die Bewegung der Arbeiter weit mehr bedeutet und weit größere Kraft und Entschlossenheit besitzt als alle bürgerlichen Bewegungen" und den Eindruck hervorrief, „daß mit dem Anfang der Arbeiterbewegung der Anfang vom Ende der bestehenden Ordnung gekommen sei." Diese Schlußfolgerungen treffen aber für den betreffenden Zeitraum nicht im geringsten $\mathrm{zu}$.

${ }^{2}$ Karl Glossy, Literarische Geheimberichte aus dem Vormärz, Bd. I, S. CXXIV u. CXXXVIII.
} 
Aufklärung und Vorbildung in freien Grundsätzen mitteilte." 1 Er denunzierte sich auch des öfteren selbst bei den Kantonalbehörden. Bei der Verhaftung wurden dann bei ihm regelmäßig Namenslisten von "Jungdeutschen" gefunden. Es blieb aber den Handwerkern und Studenten sowie den schweizerischen Verwaltungsorganen verborgen, daß Aldingers Geldgeber kein geringerer als der Leiter des Mainzer Informationsbureaus war. Der Verdacht, daß es sich um einen österreichischen oder preußischen Spitzel handelte, bestand aber wenigstens bei der Züricher Polizei. ${ }^{2}$

Das Treiben der Emigranten mißfiel auf die Dauer auch der Bevölkerung, besonders wenn die politischen Flüchtlinge, wie das in Zürich oft der Fall war, in größeren Scharen in der Öffentlichkeit auftraten. Die im Anfang zweifellos vorhandene Begeisterung für diejenigen Ausländer, die als Märtyrer im Kampfe für die Freiheit angesehen oder wegen ihres Fleißes und Könnens nicht nur im Handwerk, sondern auch in der Verwaltung herangezogen wurden, flaute erheblich ab. Die konspirative Tätigkeit, von der manche Emigranten nicht lassen wollten, rief immer wieder die Empörung der schweizer Gastgeber hervor. Ein kritischer Betrachter machte einen Unterschied zwischen wirklichen Flüchtlingen, ,im Durchschnitt sehr achtbare, hin und wieder etwas überspannte Jünglinge und Männer, die... sich ihren Unterhalt auf anständige Art verdienten..." und Pseudoflüchtlingen, die ,mit wenigen Ausnahmen Tagediebe und Vagabunden” waren, die "Schulden oder sonstiger übeln Verhältnisse halber ihr Vaterland quittiert hatten und in der Schweiz ein Eldorado zu finden wähnten”, sich „für Verfolgte, Unterdrückte, aus Gefängnissen entsprungene, für Teilnehmer an dem Frankfurter Überfall und Gott weiß für was” ausgaben, „um von den bemittelteren und tätigeren Landsleuten unterstützt zu werden." 3 Aber gerade diese Elemente zogen die Aufmerksamkeit auf sich, wurden als die eigentlichen Repräsentanten ihrer Vereine angesehen und schadeten dadurch der gesamten Bewegung. Große Teile der Bevölkerung hatten daher volles Verständnis dafür, wenn gegen diese Emigranten polizeiliche Maßnahmen ergriffen wurden.

Ein verhängnisvolles Ereignis wirkte sich zum Schaden der Flücht-

- Der Mord verübt an Ludwig Lessing aus Freienwalde, gewesener Rechtskandidat an der Universität in Zürich, oder aktenmäßige geschichtliche Darstellung der gegen den Zacharias Aldinger von Dörzbach, angeblichen Baron von Eyb und übrige Eingeklagte, deshalb geführten Untersuchung nebst Entscheidungsgründen und Urteil des Kriminalgerichtes des Kantons Zürich, Zürich I 837 , S. I 8.

${ }^{2}$ Fritz Reinöhl, Die österreichischen Informationsbüros des Vormärz, ihre Akten u. Protokolle, in: Archivalische Zeitschrift, Bd. 38 (1929), S. 263.

[August Jaeger,] Schweizerskizzen, Leipzig 1838, S. 50-51. 
linge aus. In der Nacht vom 3. zum 4. November I835 fand man in einer Straße Zürichs den preußischen Studenten Ludwig Lessing, von zahlreichen Dolchstichen durchbohrt, tot auf. Lessing hatte sich in den jungdeutschen Versammlungen immer äußerst radikal und aggressiv aufgeführt. In Wirklichkeit war er ein Spitzel der preußischen Polizei, der über das Treiben der Flüchtlinge regelmäßig Bericht erstatten mußte. Die Behörden in Bern, die Lessings Tätigkeit rechtzeitig durchschauten, hatten die Handwerker auch des öfteren vor ihm gewarnt.

Eine Untersuchungskommission stellte fest, daß es sich hier um keinen Raubmord handelte, da der Tote Geld und Wertsachen bei sich hatte. 1 Der Verdacht fiel sofort auf die Emigrantengruppen. Strenge Untersuchungen setzten ein. Auch die Studenten Ehrhardt und Cratz wurden in die Vernehmungen mit hineingezogen, denn Ehrhardt hatte kurz vorher ein Duell mit Lessing ausgefochten, wobei Cratz sekundierte. Beide kamen aber als Täter nicht in Frage und wurden lediglich wegen Verstoßes gegen die Duellgesetze zu einer geringen Geldbuße und kurzen Gefängnisstrafe verurteilt. Auf Aldinger fiel ebenfalls ein Verdacht, aber auch bei ihm ließ sich nichts nachweisen, wenn auch seine üble Rolle als „agent provocateur" ans Licht kam. ${ }^{2}$ Der Mord konnte nicht aufgeklärt werden. Es tauchten auch Gerüchte auf, daß es sich um einen Racheakt aus Eifersucht gehandelt hätte, ja sogar die preußische Polizei wurde beschuldigt, das Verbrechen selbst begangen zu haben, um einen kompromittierten Mitarbeiter loszuwerden. ${ }^{3}$ Es blieb aber ein hoher Grad von Wahrscheinlichkeit bestehen, daß die Mörder - denn es handelte sich zweifellos um mehrere Personen - in den Kreisen derjenigen Emigranten zu suchen waren, die Verbindungen angehörten, deren Satzungen für Verrat die Todesstrafe vorsahen. Der spätere Mitarbeiter Wilhelm Weitlings, August Becker, ein Gegner dieser Art von Geheimbündelei, vertrat auf Grund persönlicher Beobachtungen und Erlebnisse an Ort und Stelle sogar die feste Überzeugung, daß es sich nur um Mitglieder des „Jungen Europa” gehandelt haben könnte. 4 Ähnlich

'Claire von Glümer, Aus einem Flüchtlingsleben, S. 157.

${ }^{2}$ Für Einzelheiten s. Aktenmäßige Darstellung der über die Ermordung des Studenten Lessing geführten Untersuchungen von Dr. Joseph Schönberg, Zürich I 837. Außerdem: Der Mord verübt an Ludwig Lessing..., Zürich 1 837, S. 62 ff.

${ }^{3}$ Schmidt, Die deutschen Flüchtlinge in der Schweiz, S. 145. Schmidt neigt, ohne allerdings zu überzeugen, der Auffassung zu, daß es sich um einen persönlichen Racheakt ohne politischen Hintergrund gehandelt habe.

- August Becker, Geschichte des religiösen und atheistischen Frühsozialismus. Erstausgabe des von August Becker I 847 verfaßten und von Georg Kuhlmann eingelieferten Geheimberichts an Metternich und von Vinets Rapport. Nebst einer Einleitung herausgegeben von Ernst Barnikol, Kiel 1932, S. 47. 
äußerte sich auch der damals im Exil lebende demokratische Schriftsteller und spätere Politiker Jakob Venedey. ${ }^{\mathbf{I}}$

Alle diese Tatsachen, die Ermordung Lessings, der verschärfte Druck des Deutschen Bundes besonders seit dem Steinhölzlifest, Besorgnisse um die eigene Sicherheit, aber auch der allgemeine Umschwung der öffentlichen Meinung gegenüber den Flüchtlingsvereinen, veranlaßten jetzt die Kantonalbehörden, mit schärfsten Mitteln durchzugreifen. Die Mehrheit der Tagsatzung faßte den Beschluß, daß „diejenigen Flüchtlinge oder andere Fremden, welche die ihnen von den Ständen zugestandene Zuflucht mißbraucht und die innere Sicherheit und Ruhe oder die Mentalität der Schweiz und ihre völkerrechtlichen Verhältnisse durch Handlungen, die gehörig erhoben worden sind, gefährdet haben, aus dem schweizerischen Gebiet unter Mitwirkung des Vororts ausgewiesen werden" sollten. ${ }^{2}$

Dieser Aufforderung kam die Polizei bereitwilligst nach. In kurzer Zeit waren die "gefährlichen" Vereine aufgelöst, und viele Mitglieder, soweit man ihrer habhaft werden konnte, wurden ausgewiesen. Der sogenannten „Flüchtlingshatz” war Erfolg beschieden. Etwa I 36 Fremde, meistens Deutsche, mußten die Kantone ohne Verzug verlassen, in denen sie ihren Wohnsitz hatten. Unter den Ausgewiesenen befanden sich auch Rauschenplatt, Kombst, Fein, Harro Harring und Karl Mathy.

Die Zeitung „Die Junge Schweiz - La Jeune Suisse” stellte auf behördliche Weisung hin ihr Erscheinen ein, wie überhaupt jegliche schriftliche Propaganda erschwert wurde. Von den jungdeutschen Gemeinden blieben nur Reste übrig, die hauptsächlich in den französischen Kantonen in der Nähe des Genfer Sees ein kümmerliches Dasein fristeten, ohne in der Lage zu sein, ihren alten Einfluß wieder zu erlangen. Damit war die Rolle des "Jungen Deutschland" in der Form, wie sie zuerst Mazzini, dann die Studenten, Journalisten und Schriftsteller vertreten hatten, ausgespielt. Verschärfte Grenzsperren erschwerten außerdem den Zuzug aus Deutschland. Noë schrieb allerdings skeptisch, daß durch die schweizer Ausweisungen zwar viel für die gute Sache geschehen sei, ,aber niemand, der die geheime Kette der noch keineswegs ausgerotteten politischen Sekten kenne, werde glauben, daß sie in ihren Bemühungen nachgelassen haben." 3

${ }^{1}$ Hermann Venedey, Jakob Venedey, Darstellung seines Lebens und seiner politischen Entwicklung bis zur Auflösung der ersten deutschen Nationalversammlung i 849, Phil. Diss., Freiburg i. Br. 1930, S. 24 f.

2 Tagsatzungsbeschluß vom I r. August 1836 . Johannes Dierauer, Geschichte der Schweizerischen Eidgenossenschaft, Bd. 5, Gotha I917, S. 589.

Bericht vom Io. Oktober 1836 . Karl Glossy, Literarische Geheimberichte aus dem Vormärz, Bd. I, S. 1. 
Nach einiger Zeit verminderten sich aber die scharfen Kontrollen, so daß doch noch mancher Geselle auch von der deutschen Seite her in die Schweiz gelangen konnte. Der preußische Gesandte in Bern, von Rochow, gab auch mißbilligend zu bedenken: „Von preußischen Arbeitern säubere ich dies Land aber nachgerade, denn ich weise alles unnachsichtig fort und habe nur zu klagen, daß meine Nachbarn oft Pässe hierher visieren, ohne daß ihnen die Befugnis zusteht!" 1

Wenn auch die Grenzüberwachung nicht mehr so streng gehandhabt wurde, so trug sie aber wesentlich dazu bei, daß nicht nur die Agitation, sondern auch die Werbung von Gesinnungsgenossen vorläufig ins Stocken geriet. Denn die meisten Handwerksburschen wollten ja wieder in die Heimat zurück und hüteten sich jetzt, politischen Organisationen beizutreten, deren Mitgliedschaft ihnen zu Hause Unannehmlichkeiten bereiten konnte. Das Zentrum der Emigration verschob sich auch immer mehr aus den leicht zu übersehenden schweizer Kantonen nach Frankreich, bis auch hier polizeiliche Vorkehrungen der politischen Aktivität immer mehr Hindernisse in den Weg legten.

Nachdem die "Flüchtlingshatz" abgeklungen war, kam es 1837 in Genf zu einem neuen Zusammenschluß der noch übriggebliebenen wenigen "Jungdeutschen". Ein neuer Verein wurde gegründet, der sich wiederum das "Junge Deutschland" nannte. Aber nur der Name sollte an die frühere Verbindung erinnern. Sonst hatte sich viel geändert. Es wurde zwar noch eine gewisse revolutionäre Tradition gepflegt, wie die Erinnerung an Mazzinis Wirken und die Zusammenkunft von Steinhölzli; das Schwergewicht der Vereinstätigkeit lag aber in den Lese- und Gesangszirkeln und in der geselligen Zusammenkunft. Polizeiliche Überwachung ließ es ohnehin ratsam erscheinen, in der Öffentlichkeit nicht wieder allzu viel Aufmerksamkeit zu erregen. Als Mitglieder wurden jetzt grundsätzlich nur Handwerker, Arbeiter und Gesellen aufgenommen. ${ }^{2}$ Von den intellektuellen Flüchtlingen wollte man nichts mehr wissen. Die Erbitterung gegen sie war gewachsen, da sich in den Handwerkerkreisen die nicht unberechtigte Ansicht verbreitet hatte, daß die Gutmütigkeit und Opferwilligkeit, besonders der wandernden Gesellen, gerade von den früheren Führern zu äußerst eigensüchtigen Zwecken mißbraucht

${ }^{1} \mathrm{v}$. Rochow an Kelchner, 20. März 1837 , in: Briefe des preußischen Generals und Gesandten Theodor Heinrich Rochus von Rochow. Als Beitrag zux Geschichte des 19. Jahrhunderts herausgegeben von E. Kelner u. K. Mendelssohn-Bartholdy, Frankfurt a. Main 1874, S. 84.

"Wilhelm Marr, Das Junge Deutschland in der Schweiz, S. $7^{6}$. 
worden waren. Bald zählte der Genfer Verein etwa roo Mitglieder, nicht nur ehemalige "Jungdeutsche", sondern auch Handwerker, die bisher keinem Verein angehört hatten. ${ }^{1}$

Für die Mitglieder des Lesezirkels bildete die linksliberal eingestellte Zeitschrift „Deutsche Volkshalle” eine Pflichtlektüre. ${ }^{2}$ Ihr Herausgeber war Georg August Wirth, der in diesem Organ nach wie vor seine alte Zielsetzung propagierte: die nationale Einheit auf republikanischer Grundlage. Seine früheren Bedenken gegen Frankreich, die er schon auf dem Hambacher Fest im Mai 1832 geäußert hatte, ${ }^{3}$ kamen immer wieder zum Ausdruck. Er warf der französischen Nation vor, den deutschen Einigungsprozeß zu stören. In der kleinen Bibliothek des Lesezirkels fanden sich außer einem Konversationslexikon noch Rottecks Geschichte ${ }^{4}$ und die Dichtungen von Harro Harring, die ja gerade in Handwerkerkreisen besonders beliebt waren.

Unter dem Eindruck der Verfolgungen von $18{ }_{3} 6$ verhielten sich die "Jungdeutschen" sehr zurückhaltend. Die Furcht vor Spitzeln führte zunächst auch zu einer vorsichtigen Stellungnahme gegenüber jeglicher politischen Tätigkeit. Die Verbindung zu den Pariser Geheimverbänden, die sich schon vorher gelockert hatte, brach ganz ab. Die einzige politische Willensäußerung blieb das Zurschautragen der schwarz-rot-goldenen Farben, sei es als Uhrband oder Pfeifenkopf, als Ansteckzeichen oder Wappen. ${ }^{5}$ Die jungdeutschen Bildungsund Lesevereine würden wegen ihrer Bedeutungslosigkeit auch bald in Vergessenheit geraten sein, wenn nicht neue Anregungen von anderer Seite gekommen wären.

In Genf trafen zwei deutsche Intellektuelle ein, die sich um eine Neuorganisierung des Vereinswesens bemühten: August Becker und Weitzel. Der ehemalige Theologe Becker war ein Mitarbeiter des liberalen Rektors Weidig aus Butzbach, der im Großherzogtum Hessen und bei Rhein eine Geheimgesellschaft gegründet und durch Flugschriften den Widerstand gegen die Regierung geschürt hatte.

'S. Otto Brugger, Geschichte der deutschen Handwerkervereine in der Schweiz, S. 34.

Die Zeitschrift erschien bis 1841 .

${ }^{3}$ In seiner Hambacher Rede vom 27. Mai 1832 beschuldigte Wirth z. B. die regierenden Kreise in Frankreich, aus kleinlichen materiellen Interessen die Reformbestrebungen in Deutschland nicht zu fördern bzw. als Preis für eine mögliche Hilfe das gesamte linke Rheinufer zu verlangen. J. G. A. Wirth, Das Nationalfest der Deutschen in Hambach, Neustadt a.H., 1832 (Photomechanischer Nachdruck der Originalausgabe, Neustadt an der Weinstraße 1957), S. 44.

- Karl Wenzeslaus von Rotteck, Allgemeine Weltgeschichte. Es handelt sich um einen 1835 erschienenen vierbändigen Auszug der zuerst in den Jahren 1812-1818 veröffentlichten "Allgemeinen Geschichte".

- August Becker, Geschichte des religiösen und atheistischen Frühsozialismus, S. 32. 
Nach Weidigs Verhaftung und Selbstmord kam Becker wegen Verteilung des berühmten Flugblattes von Georg Büchner ${ }^{1}$ ins Gefängnis. Er wurde aber nach kurzer Zeit begnadigt und ging nach Genf, wo er sich als Lehrer und Schriftsteller seinen Unterhalt verdiente. Hier machte er auch die Bekanntschaft von Wirth, für dessen Zeitschrift er des öfteren Artikel verfaßte. Weitzel war Organist an der deutschen Kirche in Genf. Er beabsichtigte, einen Bildungs- und Unterhaltungsklub für Handwerksgesellen zu gründen. ${ }^{2}$ Seine Pläne trafen sich mit denen Beckers, der darüber hinaus noch eine weitumspannende Vereinigung aufbauen wollte, die sich der Aufgabe widmen sollte, das intellektuelle und sittliche Niveau der Handwerker zu heben. Becker plante auch, Mitarbeiter aus den gebildeten Ständen für seine „Arbeiter-Akademie” heranzuziehen. Auf der Suche nach einer schon vorhandenen Organisationsgrundlage stieß er sofort auf die jungdeutschen Sing- und Lesezirkel. Hier brachten er und Weitzel entsprechende Vorschläge zur Sprache, ohne aber zunächst auf Gegenliebe zu stoßen.

Denn die Persönlichkeit des Organisten, eines tief religiösen Menschen, war den "Jungdeutschen" verdächtig, die Besorgnisse hatten, Weitzel könnte dem gesamten Verein eine ausgesprochen pietistische Note geben. Dazu kam, daß Becker nicht nur deutsche, sondern auch schweizer Handwerker und Arbeiter aufnehmen wollte, was den Widerstand aller Beteiligten hervorrief. Denn die "Jungdeutschen" betrachteten ihren Zirkel als ein deutsches Propagandazentrum und hielten die Aufnahme von Schweizern nicht nur für nutzlos, sondern auch für gefährlich, weil sie die Einheit stören würde. Die Schweizer legten dagegen eine allgemeine Ablehnung gegen die „Schwaben” an den Tag, denen sie sich überlegen fühlten. Außerdem brachen noch innere Zwistigkeiten aus. Die Goldarbeiter und Uhrmacher unter den Handwerkern hielten es für unter ihrer Würde, mit Schneidern und Schuhmachern private Geselligkeit zu pflegen. Und schließlich verweigerten die vorgesehenen Lehrkräfte ihre Mitarbeit. Sie erklärten sich zwar bereit, Geldbeträge für den Aufbau der „Arbeiter-Akademie" zu stiften, lehnten es aber ab, in einem Verein zu unterrichten, dessen Mitglieder hauptsächlich aus wenig vorgebildeten Handwerksburschen bestanden. ${ }^{3}$

Erst nach hartnäckigen Auseinandersetzungen gelang es Becker, mit seinem Argument durchzudringen, die Aufnahme von Schweizern

${ }^{1}$ Der Hessische Landbote, Darmstadt im Juli 1834. Georg Büchner, Werke und Briefe. Neue durchgesehene Ausgabe, herausgegeben von Fritz Bergemann, Wiesbaden 1958, S. 333 ff.

${ }^{2}$ Otto Brugger, Geschichte der deutschen Handwerkervereine in der Schweiz, S. 35.

3 August Becker, Geschichte des religiösen und atheistischen Frühsozialismus, S. 33. 
würde einen gewissen Schutz vor Behelligungen durch die Kantonalpolizei bieten. Widerwillig stimmten die "Jungdeutschen" schließlich $\mathrm{zu}$, als in den Statuten die Bestimmung aufgenommen wurde, jeder Bewerber, der die deutsche Sprache beherrsche, könne Mitglied werden, gleichgültig, ob es sich um einen Deutschen oder Schweizer handele. Am ro. November 1839 wurde die neue Vereinigung schließlich ins Leben gerufen. ${ }^{1}$ Beinahe wäre es noch zu einem Bruch gekommen, als durch die Initiative von Weitzel der Verein für unpolitisch erklärt wurde. Die "Jungdeutschen" drohten daraufhin sofort mit ihrem Austritt. Durch eine geschickte Auslegung der in Frage kommenden Artikel gelang es aber, diese Abwanderung zu verhindern. Der betreffende Abschnitt lautete jetzt: „Der Verein ist kein politischer, d.h. er mischt sich nicht in die praktische Politik, er konspiriert nicht, macht keine politische Propaganda, verlangt kein politisches Glaubensbekenntnis von seinen Mitgliedern, schließt aber die Politik, als Wissenschaft betrachtet, nicht aus. ${ }^{2}$

Bald zählte der neue Verein an die 150 Mitglieder. Außerdem wurde eine Verpflegungsanstalt eröffnet, die Wirth in eigener Rechnung verwaltete. ${ }^{3}$ Uber das Treiben in den Vereinsräumen berichtete Becker: „Dort sah man sich mittags und unterhielt sich an der munteren Tafel über die in den Zeitungen enthaltenen Neuigkeiten. Abends und sonntags morgens besuchten einige die Lehrstunden..., oder sie unterhielten sich im Lesezimmer oder plauderten oder spielten Schach im Gesellschaftszimmer oder sie nahmen am Sing-Unterricht teil, der ebenfalls in einem besonderen Zimmer erteilt wurde, und das alles für I Franken oder 28 Franken pro Monat." 4

An Unterstützung fehlte es jetzt nicht. Wohlhabende Bürger spendeten Geld und Bücher. Allmählich stellten sich auch Lehrkräfte gegen Bezahlung ein und gaben Unterricht in französischer Sprache, Geschichte, Geographie, Mathematik, Physik, Gesang und Zeichnen. Die Genfer Behörden betrachteten diese Tätigkeit der „Arbeiter-Akademie" mit einem gewissen Wohlwollen. In einem Polizeibericht hieß es: „Das geistige Leben gewann immer mehr Zuwachs, diejenigen, welche die Vereine besuchten, änderten fast sichtbar ihre Lebensweise... Die Leidenschaft des Lärmmachens in den Gassen und der Schlägereien nahm durch die Vereine eine edlere Richtung an.

1 Generalbericht des Herrn A. Faure, Zentralpolizeidirektor und D.S.U. Lardy, Maire von Les Ponts an den Stadtrat von Neuchâtel über die geheime deutsche Propaganda, über die Klubs des jungen Deutschland und über den Lemanbund, in: Eidgenössische Monatsschrift, Zürich I846, Heft 4, S. II.

2 August Becker, Geschichte des religiösen u. atheistischen Frühsozialismus, S. 34.

3 Wilhelm Marr, Das junge Deutschland in der Schweiz, S. 9r f.

- August Becker, Geschichte des religiösen und atheistischen Frühsozialismus, S. $34 \mathrm{f}$. 
Die rohen Aufzüge unterblieben allmählich und die freundlichen Verhältnisse zwischen Einheimischen und Auswärtigen wurden dadurch verstärkt." 1

Das politische Leben in Genf gestaltete sich jetzt für die Handwerker überhaupt freier. Denn hier hatte ja Babeufs Mitverschworener Buonarroti längere Zeit gelebt. Von seinen Schülern waren manche in der Schweiz zu Ehren gekommen, vor allem Jean Jakob (genannt James) Fazy, ein liberaler Politiker und Journalist, der I84I in Genf die Annahme einer demokratischen Verfassung durchsetzte und später als Leiter der Regierung für den Ausbau und die Modernisierung der Stadt viel geleistet hatte. ${ }^{2}$

Auch außerhalb Genfs bildeten sich in der französischen Schweiz weitere Vereinigungen, die eine durchaus eigene Prägung aufwiesen und ebenfalls in der Form von Gesangs- und Lesezirkeln aufgezogen wurden. ${ }^{3}$ In den deutschen Kantonen entstanden ähnliche Klubs in Winterthur, Zürich, Luzern und Basel, die aber nicht die gleiche Bedeutung erhalten sollten.

Der sozialistische Einfluß in allen diesen Gruppen war verhältnismäßig gering, ausgenommen der Lausanner Verein, dessen Seele der Gerber Simon Schmidt war. Er propagierte von vornherein stark sozialistische und auch kommunistische Gedankengänge, ${ }^{4}$ die in der handgeschriebenen Vereinszeitung „Der volkstümliche Handwerker” unter dem Motto: Gleichheit = Verbrüderung, Freiheit = Einheit, Erziehung $=$ Sittlichkeit, Arbeit $=$ Ordnung verkündet wurden. ${ }^{5}$ „Der volkstümliche Handwerker ist Reformist, Sozialist und Gemeinschaftler, d.h. er öffnet seine Spalten allen wohlwollenden Ansichten in bezug auf das Gemeinwohl", stellte Schmidt fest und propagierte Gerechtigkeit, Sittlichkeit und Duldsamkeit als Richtlinien. ${ }^{6}$ Er verkündete auch eine allgemeine Völkerverbrüderung und forderte die Ausrottung des Nationalhasses, der durch die Lehre von der Solidarität der Völker im Bereiche der gesamten Menschheit

\footnotetext{
1 Brugger, Geschichte der deutschen Handwerkervereine in der Schweiz, S. 42.

${ }^{2}$ Aus der Reihe der Buonarrotischen Schüler wären noch erwähnenswert der ehemalige Leiter der „Jungen Schweiz", Henry Druey, später Staatsrat im Kanton Waadt, und Louis Henry Delarageaz, der als Führer der radikalen Partei 1845 die Regierung in Genf stürzte.

${ }^{3}$ Es entstanden Vereine in Lausanne, Morges (Morsee), Vevey (Vivis), Aigle, Nyon, Yverdon, Neufchâtel, La Chaux de Fonds, Locle, Aubonne und Rolle.

- August Becker, Geschichte des religiösen und atheistischen Frühsozialismus, S. I03.

5 Der vollständige Titel der Zeitschrift lautete: „'Der volkstümliche Handwerker'. Journal der gesellschaftlichen und politischen Wiederherstellung für den volkstümlichen Handwerkerverein in Lausanne und unter dessen Leitung herausgegeben."

B August Becker, Geschichte des religiösen und atheistischen Frühsozialismus, S. 59 f.
} 
ersetzt werden sollte. Aber auch dem aufkeimenden Klassenbewußtsein, dem Verlangen der Armen und Rechtlosen, der Arbeiter und Handwerker wurde Ausdruck gegeben.

Aus den Reihen des Lausanner Vereins erhob ein Mitglied auch die Forderung, den Versuch zu unternehmen, das „Selbstbewußtsein der Arbeiter zu wecken, denn nur aus unserer Mitte wird eine glücklichere Zukunft erstehen..." Dieser Handwerker - es handelte sich um einen Schreiner - beschwor seine Kollegen: „Vertrauen wir auf uns selbst, damit nicht unsere Rechte in die Hände von einzelnen zu liegen kommen und daß nur dadurch uns vielleicht nach vollbrachtem Kampfe der Sieg entwendet werde..." 1 Allerdings waren die Anschauungen Simon Schmidts und seines persönlichen Anhangs durchaus gemäßigt, da sie keine Revolution, sondern lediglich Reformen anstrebten. ${ }^{2}$

Interne Auseinandersetzungen um künftige Zielsetzungen führten aber im jungdeutschen Verein bald zu einer Abspaltung der schweizer Mitglieder, die sich von den Deutschen trennten und den sogenannten Grütliverein gründeten, in dem grundsätzlich nur Einheimische aufgenommen wurden. Die Ziele dieser neuen Gruppe waren begrenzt, da sie ihre Propaganda bewußt lediglich auf die Schweiz beschränkten und nur Kantonalprobleme zur Diskussion stellten, wobei sie ausgesprochen nationale Tendenzen vertraten. ${ }^{3}$

August Becker war über die Trennung von den Schweizern äußerst erregt und betonte immer wieder, daß beide Teile verloren hätten. Er stellte den schweizer Handwerkern das Zeugnis aus, sie wären geschickt in allen Dingen des praktischen Lebens, würden sich aber gegenüber den Deutschen durch Egoismus, Unzugänglichkeit und Mißtrauen auszeichnen. Die deutschen Handwerker schilderte Becker als treuherzig und fleißig, aber auch als leichtsinnig, unpraktisch und vielfach unklaren Ideen anhängend. Et räumte aber ein, daß diese Eigenschaften das schweizerische Wesen gut ergänzen würden.

Becker machte sich auch darüber Gedanken, daß lediglich die Anwesenheit der Schweizer den Deutschen eine gewisse Sicherheit

\footnotetext{
${ }^{1}$ Aus einem Briefe des Dänen Niels Schack, Mitglied des Lausanner Vereins, an Julius Standau in Winterthur, 24. Januar I 84I. Abgedruckt bei Brugger, Geschichte der deutschen Handwerkervereine in der Schweiz, S. 67.

2 Simon Schmidt stellte kein selbständiges Programm auf. Er stand stark unter dem EinfluB des radikal gesinnten schweizer Politikers Georges Kehrmand, eines Mitglieds des Großrats und des Patronatskomitees für den Flüchtlingsverein. Kehrmand gehörte zu den Schülern Buonarrotis, als dieser sich noch in Genf aufhielt. S. den Rapport Vinets bei Becker, Geschichte des religiösen und atheistischen Frühsozialismus, S. 103.

3 [Albert Galeer,] Der moralische Volksbund und die freie schweizer Männerschule oder der Grütliverein, Genf I846, S. 47 f.
} 
gegeben hätte, die jetzt wegfiel. Denn die schweizer Mitglieder hatten immerhin die Möglichkeit, bei einem drohenden polizeilichen Verbot von ihren Rechten Gebrauch zu machen und durch richterlichen Einspruch eine Auflösung des Vereins zumindest zu erschweren.

Auf das übertrieben nationale Pathos des Grütlivereins und seiner Zweigstellen ging Becker aber nur mit Spott ein, weil die sogenannte Heldenzeit der Schweiz lediglich ein Phantasiegebilde von Schiller sei und die moralischen Reden des theatralischen Wilhelm Tell die Kritik der praktischen Vernunft des Professors Kant in Königsberg passiert hätten. ${ }^{1}$

Der deutsche Handwerkerverein in Genf konnte sich aber noch weiter behaupten, obwohl er durch den Auszug der Schweizer über ein Drittel seines Mitgliederbestandes eingebüßt hatte. Die Gesamttätigkeit der Genfer Gruppen und der in anderen Städten kam aber ins Stocken. Der Stillstand wurde noch durch die von Wirth publizistisch vertretenen Doktrinen gefördert. Seine Auffassungen entsprachen auf die Dauer nicht mehr denen der Handwerker. Diese Art von Propaganda wirkte etwas blutleer, weil ihr nicht nur jeder wirtschaftliche Hintergrund fehlte, sondern auch eine soziale Erkenntnis der Gesamtlage. Wirth hatte auch keinen Blick für die sich materiell immer mehr verschlechternden Verhältnisse, unter denen die Handwerksburschen zu leiden hatten. Der von ihnen so ersehnte Aufstieg in den Meisterstand wurde so erschwert, daß sich viele von ihnen der anwachsenden Schar der Proletarier anschließen mußten. Eine Ergänzung der alten jungdeutschen Theorien in der Richtung wirtschaftlich-sozialer Gedankengänge erwies sich daher immer mehr als notwendig. Der Weg war frei für neue Wortführer.

Als Wilhelm Weitling im Mai $184 \mathrm{I}$ in der Schweiz seine Zuflucht suchte und fand, sah er sich einer Situation gegenüber, die ihn in der Úberzeugung bestärkte, daß er hier einen guten Boden für seine Lehren finden würde. Denn hier waren ja schon seit Buonarrotis Zeiten gewisse Vorarbeiten geleistet und daher kommunistische Grundelemente vorhanden. So fiel es Weitling nicht schwer, durch intensive kommunistische und revolutionäre Propaganda den richtungslos gewordenen deutschen Vereinen eine Zielsetzung zu geben, die ihnen neue Wege weisen und einen festen Glauben geben sollte.

${ }_{1}$ August Becker, Geschichte des religiösen und atheistischen Frühozialismus, S. 42. 